\title{
An Alternative Ranking Approach and Its Usage in Multi-Criteria Decision-Making
}

\author{
Cengiz Kahraman \\ Industrial Engineering Department, Istanbul Technical University, \\ Maçka, Besiktas, Istanbul, 34367, Turkey \\ A. Cagri Tolga* \\ Industrial Engineering Department, Galatasaray University, \\ Ortaköy, Besiktas, Istanbul, 34357, Turkey \\ E-mail: ctolga@gsu.edu.tr \\ www.gsu.edu.tr
}

Received: 19/11/08

Accepted: 13/05/09

\begin{abstract}
In the process of fuzzy decision-making, ranking of fuzzy numbers is a necessity. The types of fuzzy numbers are triangular, trapezoidal, and L-R type. In the literature, there are many methods developed for ranking fuzzy numbers. These methods may produce different ranking results. Many of these methods necessitate graphical representations, complex and tedious calculations. The method developed in this paper has some advantages with respect to the other methods in both graphical representations and calculations. Applicability of the proposed method to multi-criteria decision-making methods, i.e. fuzzy scoring, fuzzy AHP and fuzzy TOPSIS methods, is shown in the paper.
\end{abstract}

Keywords: Fuzzy numbers, ranking, decision-making, TOPSIS, scoring, AHP.

\section{Introduction}

The term fuzzy number is employed to cope with vague numerical quantities, like "nearly 9", "more or less 3", "several", etc. A general definition of a fuzzy number is given by Dubois and Prade' ${ }^{1}$ : any fuzzy subset $A=\left\{\left(x, m_{A}(x)\right)\right\}$ where $\mathrm{x}$ takes its number on the real line $\mathrm{R}$ and $\mu_{A}(x) \in[0,1]$. The membership function denotes the degree of truth that $A$ takes a specific number $x^{\prime}$.

In many cases, the use of extension principle operations on fuzzy numbers tends to be cumbersome ${ }^{2}$. Thus, special fuzzy numbers are proposed to reduce the amount of computational effort. Triangular fuzzy numbers, trapezoidal fuzzy numbers, L-R triangular fuzzy numbers, and L-R trapezoidal fuzzy numbers are the special numbers that have been used in miscellaneous decision models.

In fuzzy set literature, ranking fuzzy numbers is much investigated because of its wide usage area in decisionmaking. It is a necessity to rank the obtained fuzzy numbers in a decision-making problem. The ranking methods can be classified in three categories. The first category directly transforms each fuzzy number into a crisp real number and the second category compares a fuzzy number to all the other $n-1$ fuzzy numbers to

*Corresponding author: ctolga@gsu.edu.tr, Tel: +90212 2274480 Ext.433. 
obtain its mapping into a positive real number. The third category differs substantially from the first two. In this category, a method for pair wise ranking or preference for all pairs of fuzzy numbers is determined and then based on these pair wise orderings, a final order of the $n$ fuzzy numbers is attempted ${ }^{3}$.

The investigation on ranking fuzzy numbers began early 70's. Many researchers have classified fuzzy ranking methods since 1980. First Freeling ${ }^{4}$ proposed five categories for ranking methods: (a) methods using extended maximum; (b) methods using implication logic; (c) methods using preference relations; (d) methods of direct comparison and; (e) linguistic approaches. Bortolan and Degani ${ }^{5}$ dealt with the problem of ranking $n$ fuzzy subsets of the unit interval. They reviewed a number of methods suggested in the literature and tested on a group of selected examples, where the fuzzy sets can be non-normal and/or nonconvex. Lee and $\mathrm{Li}^{6}$ broadly categorized ranking methods as mathematical approaches versus linguistic approaches. From these classifications, Chen et al. ${ }^{2}$ introduced a categorization of fuzzy ranking methods that was composed of four major classes and their subclasses: (i). preference relation methods (degree of optimality, hamming distance, $\alpha$-cut, and comparison function), (ii). fuzzy mean and spread method (probability distribution), (iii). fuzzy scoring (or direct comparison) methods (proportion to optimal, left/right scores, centroid index, area measurement), and (iv). linguistic methods (intuition, linguistic approximation).

The aim of this paper is to develop a new ranking method which is reliable and does not need tremendous arithmetic calculations. We propose an area measurement based method for ranking fuzzy numbers. This method is very easy to use with respect to the complexity of many other methods. Our method is similar to Fortemps and Roubens" ${ }^{, 7}$ area compensation method but more compact with much less computational effort. Our method is interested in ranking triangular and trapezoidal fuzzy numbers while Fortemps and Roubens ${ }^{7}$ method can also rank L-R type fuzzy numbers.

Aiming at showing the application of the developed ranking method, it is used in three well-known multicriteria decision making methods in our paper. The Multi Criteria Decision Making is a discipline aimed at supporting decision makers who are faced with making numerous and conflicting evaluations. It aims at highlighting these conflicts and deriving a way to come to a compromise in a transparent process. The considered multicriteria methods are fuzzy scoring method, fuzzy analytic hierarchy process (AHP) method, and fuzzy TOPSIS method.

The rest of the paper is organized as follows: in Section 2, a literature review on ranking methods is given. The descriptions of all types of fuzzy numbers are presented in Section 3. At the fourth section, the proposed area-based ranking method is represented. Investigation with respect to specific axioms on ranking fuzzy numbers is presented in Section 5. The sixth section belongs to the applications of the proposed ranking method to three decision-making problems. We conclude the study including possible future works in the last section.

\section{Literature Review}

The works on ranking fuzzy numbers in the literature can be briefly classified as follows: The approaches using degree of optimality method: Baas and Kwakernaak $^{8}$, Watson et al. ${ }^{9}$, Baldwin and Guild ${ }^{10}$.

The approaches using hamming distance: Yager ${ }^{11}$, Kerre $^{12}$, Nakamura ${ }^{13}$, Kolodziejczyk ${ }^{14}$, Tran and Duckstein $^{15}$.

The approaches using $\alpha$-cuts: Adamo ${ }^{16}$, Buckley and Chanas $^{17}$, Mabuchi ${ }^{18}$, Chen and $\mathrm{Lu}^{19}$.

Dubois and Prade ${ }^{20}$ depicted various comparison functions for derivation of four ranking indices: a) Possibility of Dominance (PD), b) Possibility of Strict Dominance (PSD), c) Necessity of Dominance (ND), and d) Necessity of Strict Dominance (NSD). Using one or more indices the ranking order can be obtained. Other researchers using similar functions are Tsukamoto et al. ${ }^{21}$ and Delgado et al. ${ }^{22}$.

The ranking methods using generalized mean and standard deviation: Lee and $\mathrm{Li}^{6}$, Cheng ${ }^{23}$, Murakami et al. $^{24}$, Chu and Tsao ${ }^{25}$.

The method using some specified fuzzy ideals: McCahone ${ }^{26}$.

The methods using left and right scores: Jain ${ }^{27,} 28$, Chen $^{29}$, Chen and Hwang ${ }^{30}$.

The methods using centroid index: Yager ${ }^{31}$, Murakami et al. ${ }^{24}$, Yong and $\mathrm{Qi}^{32}$.

The methods using area based approaches: Yager $^{33}$, Fortemps and Roubens ${ }^{7}$. 
The methods using linguistic approaches: Efstathiou and Tong ${ }^{34}$, Tong and Bonissone ${ }^{35}$, Modarres and SadiNezhad $^{36}$
The studies mentioned above are put into Table 1 with the times cited with respect to the ranking approaches they use. The times cited show how many

Table 1. Usage frequencies of the ranking approaches.

\begin{tabular}{|c|c|c|c|c|c|}
\hline Researchers & Type of FN & $\begin{array}{l}\text { Ranking } \\
\text { approach }\end{array}$ & $\begin{array}{l}\text { Times cited } \\
\text { by other } \\
\text { researchers }\end{array}$ & $\begin{array}{c}\text { Times cited per } \\
\text { year }\end{array}$ & Order \\
\hline $\begin{array}{l}\text { Baas and } \\
\text { Kwakernaak }^{8}\end{array}$ & L-R Type & $\begin{array}{l}\text { degree of } \\
\text { optimality }\end{array}$ & 186 & $186 / 30=6.2$ & 5 \\
\hline Watson et.al. ${ }^{9}$ & L-R Type & $\begin{array}{l}\text { degree of } \\
\text { optimality }\end{array}$ & 105 & $105 / 28=3.75$ & 8 \\
\hline $\begin{array}{l}\text { Baldwin and } \\
\text { Guild }^{10}\end{array}$ & L-R Type & $\begin{array}{l}\text { degree of } \\
\text { optimality }\end{array}$ & 3 & $3 / 29=0.1$ & 28 \\
\hline Yager $^{11}$ & $\begin{array}{c}\text { Trapezoidal, } \\
\text { Triangular }\end{array}$ & $\begin{array}{l}\text { hamming } \\
\text { distance }\end{array}$ & 37 & $37 / 27=1.37$ & 18 \\
\hline Kerre $^{12}$ & L-R Type & $\begin{array}{c}\text { hamming } \\
\text { distance }\end{array}$ & 26 & $26 / 25=1.04$ & 23 \\
\hline Nakamura $^{13}$ & L-R Type & $\begin{array}{l}\text { hamming } \\
\text { distance }\end{array}$ & 58 & $58 / 21=2.76$ & 13 \\
\hline Kolodziejczyk $^{14}$ & L-R Type & $\begin{array}{c}\text { hamming } \\
\text { distance }\end{array}$ & 42 & $42 / 21=2$ & 16 \\
\hline $\begin{array}{l}\text { Tran and } \\
\text { Duckstein }^{15}\end{array}$ & L-R Type & $\begin{array}{c}\text { hamming } \\
\text { distance }\end{array}$ & 18 & $18 / 5=3.6$ & 9 \\
\hline Adamo $^{16}$ & $\begin{array}{c}\text { Trapezoidal, } \\
\text { Triangular }\end{array}$ & $\alpha$-cut & 68 & $68 / 27=2.52$ & 15 \\
\hline $\begin{array}{l}\text { Buckley and } \\
\text { Chanas }\end{array}$ & $\begin{array}{c}\text { Trapezoidal, } \\
\text { Triangular }\end{array}$ & $\alpha$-cut & 22 & $22 / 18=1.22$ & 21 \\
\hline Mabuchi $^{18}$ & Triangular & $\alpha$-cut & 20 & $20 / 19=1.05$ & 22 \\
\hline Chen and $\mathrm{Lu}^{19}$ & L-R Type & $\alpha$-cut & 8 & $8 / 6=1.33$ & 19 \\
\hline Dubois and Prade ${ }^{20}$ & $\begin{array}{c}\text { Trapezoidal, } \\
\text { Triangular }\end{array}$ & $\begin{array}{l}\text { comparison } \\
\text { function }\end{array}$ & 189 & $189 / 24=7.87$ & 1 \\
\hline Tsukamoto et al. ${ }^{21}$ & $\begin{array}{c}\text { Trapezoidal, } \\
\text { Triangular }\end{array}$ & $\begin{array}{l}\text { comparison } \\
\text { function }\end{array}$ & 7 & $7 / 24=0.29$ & 25 \\
\hline Delgado et al. $^{22}$ & L-R Type & $\begin{array}{l}\text { comparison } \\
\text { function }\end{array}$ & 37 & $37 / 19=1.95$ & 17 \\
\hline Lee and $\mathrm{Li}^{6}$ & L-R Type & $\begin{array}{c}\text { fuzzy mean and } \\
\text { spread }\end{array}$ & 75 & $75 / 19=3.95$ & 7 \\
\hline Cheng $^{23}$ & L-R Type & $\begin{array}{c}\text { fuzzy mean and } \\
\text { spread }\end{array}$ & 48 & $48 / 9=5.33$ & 6 \\
\hline Chu and $\mathrm{Tsao}^{25}$ & L-R Type & $\begin{array}{c}\text { fuzzy mean and } \\
\text { spread }\end{array}$ & 15 & $15 / 5=3$ & 11 \\
\hline McCahone $^{26}$ & L-R Type & $\begin{array}{c}\text { proportion to } \\
\text { ideal }\end{array}$ & 5 & $5 / 20=0.25$ & 26 \\
\hline Jain $^{27}$ & Triangular & $\begin{array}{c}\text { left and right } \\
\text { scores }\end{array}$ & 89 & $89 / 31=2.87$ & 12 \\
\hline Jain $^{28}$ & $\begin{array}{c}\text { Trapezoidal, } \\
\text { Triangular }\end{array}$ & $\begin{array}{c}\text { left and right } \\
\text { scores }\end{array}$ & 80 & $80 / 30=2.67$ & 14 \\
\hline Chen $^{29}$ & Triangular & $\begin{array}{c}\text { left and right } \\
\text { scores }\end{array}$ & 142 & $142 / 22=6.45$ & 4 \\
\hline Chen and Hwang ${ }^{30}$ & Triangular & $\begin{array}{c}\text { left and right } \\
\text { scores }\end{array}$ & 2 & $2 / 18=0.11$ & 27 \\
\hline Yager $^{31}$ & L-R Type & centroid index & 194 & $194 / 27=7.19$ & 2 \\
\hline Murakami et al. ${ }^{24}$ & L-R Type & centroid index & 30 & $30 / 24=1.25$ & 20 \\
\hline Yager $^{33}$ & L-R Type & $\begin{array}{c}\text { area } \\
\text { measurement }\end{array}$ & 173 & $173 / 26=6.65$ & 3 \\
\hline $\begin{array}{l}\text { Efstathiou and } \\
\text { Tong }^{34}\end{array}$ & $\begin{array}{c}\text { Trapezoidal, } \\
\text { Triangular }\end{array}$ & linguistic & 10 & $10 / 27=0.37$ & 24 \\
\hline $\begin{array}{l}\text { Tong and } \\
\text { Bonissone }^{35}\end{array}$ & $\begin{array}{c}\text { Trapezoidal, } \\
\text { Triangular }\end{array}$ & linguistic & 0 & 0 & 29 \\
\hline $\begin{array}{l}\text { Modarres and } \\
\text { Sadi-Nezhad }^{36}\end{array}$ & Triangular & linguistic & 19 & $19 / 6=3.17$ & 10 \\
\hline
\end{tabular}


times those studies have been cited in the literature from 1980 to 2007. Some newer studies have not been listed in Table 1 since those might have not yet been cited or discovered by many researchers. So, we put the ones before 2002 into Table 1. For example; Yong and Qi's ${ }^{32}$ study is not listed in Table 1. Ranking fuzzy numbers is still a topic that receives much attention from several researchers. Some recent works are as follows:

Abbasbandy and Hajjari ${ }^{37}$ introduce a new approach for ranking of trapezoidal fuzzy numbers based on the left and the right spreads at some $\alpha$-levels of trapezoidal fuzzy numbers. Chen and Tang ${ }^{38}$ consider ranking fuzzy numbers with integral value for the nonnormal p-norm trapezoidal fuzzy numbers. Wang and $\mathrm{Lee}^{39}$ propose a method which can avoid $\mathrm{Chu}$ and Tsao's ${ }^{25}$ problems for ranking fuzzy numbers. Since the revised method is based on the $\mathrm{Chu}$ and Tsao's ${ }^{25}$ method, it is easy to rank fuzzy numbers in a way similar to the original method. Asady and Zendehnam ${ }^{40}$ propose a defuzzication using minimizer of the distance between the two fuzzy numbers.

\section{Fuzzy Numbers}

Fuzzy numbers are a particular kind of fuzzy sets. A fuzzy number is a fuzzy set $R$ of real numbers set with a continuous, compactly supported, and convex membership function.

Let $X$ be a universal set; a fuzzy subset $\tilde{A}$ of $X$ is defined by a function $\mu_{\tilde{A}}():. X \rightarrow[0,1]$, called membership function. Throughout this paper, $X$ is assumed to be the set of real numbers $R$ and $F$ the space of fuzzy sets.

The fuzzy set $\tilde{A} \in F$ is a fuzzy number iff:

(i) $\forall \alpha \in[0,1]$ the set $A^{\alpha}=\left\{x \in R: \mu_{\tilde{A}}(x) \geq \alpha\right\}$, which is called $\alpha$-cut of $\tilde{A}$, is a convex set.

(ii) $\mu_{\tilde{A}}$ (.) is a continuous function.

(iii) $\operatorname{supp}(\tilde{A})=\left\{x \in R: \mu_{\tilde{A}}(x) \geq 0\right\}$ is a bounded set in $R$.

(iv) height $\tilde{A}=\max _{x \in X} \mu_{\tilde{A}}(x)=h \geq 0$.

By conditions (i) and (ii), each $\alpha$-cut is a compact and convex subset of $R$ hence it is a closed interval in $R$, $A^{a}=\left[A_{L}(a), A_{R}(a)\right]$. If $h=1$ we say that the fuzzy number is normal; we denote the set of normal fuzzy numbers by $N F N$ and hereafter all fuzzy numbers used in this paper will be $N F N$.

Let us show a fuzzy number $\tilde{A}=\left(a_{1}, a_{2}, a_{3}, a_{4}\right)$, $a_{1} \leq a_{2} \leq a_{3} \leq a_{4}$ in this form that will be utilized in the following definitions.
In fuzzy literature, there are three types of fuzzy numbers as denoted below:

\subsection{Left-Right fuzzy numbers}

The fuzzy number $\tilde{A}$ is a so-called Left-Right fuzzy number, $\tilde{A}=\left(a_{1}, a_{2}=a_{3}, a_{4}\right)_{L R}, \quad a_{1} \leq a_{2}=a_{3} \leq a_{4}$ if its membership function $\mu_{\tilde{A}}(x): R \rightarrow[0,1]$ is equal to:

$$
\mu_{\tilde{A}}(x)=\left\{\begin{array}{cc}
L\left(\frac{a_{2}-x}{a_{2}-a_{1}}\right) & x \in\left(a_{1}, a_{2}\right] \\
R\left(\frac{x-a_{3}}{a_{4}-a_{3}}\right) & x \in\left(a_{3}, a_{4}\right] . \\
0 & \text { others }
\end{array}\right.
$$

where $L$ and $R$, called the left and the right shape functions, are continuous and decreasing mappings from $[0,1]$ to $[0,1]$ such that $L(0)=R(0)=h>0$ and $L(1)=R(1)=0$. The value $a_{2}=a_{3}$ corresponds to the peak of $\tilde{A}$.

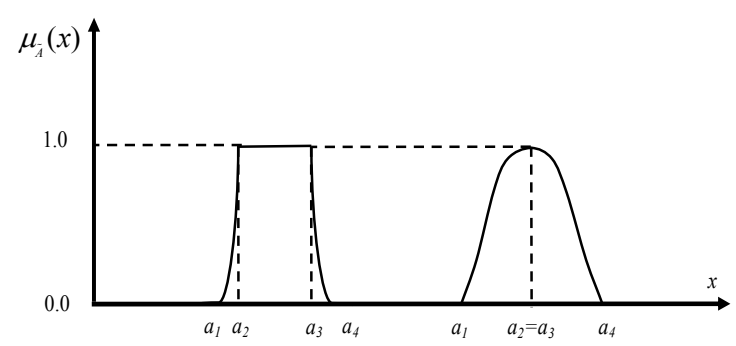

Fig. 1. Two different L-R type fuzzy numbers.

\subsection{Trapezoidal fuzzy numbers}

The fuzzy number $\tilde{A}$ is a so-called Trapezoidal fuzzy number $\quad \tilde{A}=\left(a_{1}, a_{2}, a_{3}, a_{4}\right), \quad a_{1} \leq a_{2} \leq a_{3} \leq a_{4} \quad$ if its membership function $\mu_{\tilde{A}}(x): R \rightarrow[0,1]$ is equal to

$$
\mu_{\tilde{A}}(x)=\left\{\begin{array}{cc}
\frac{x-a_{1}}{a_{2}-a_{1}} & x \in\left(a_{1}, a_{2}\right] \\
1 & x \in\left[a_{2}, a_{3}\right] \\
\frac{a_{4}-x}{a_{4}-a_{3}} & x \in\left[a_{3}, a_{4}\right) \\
0 & \text { others }
\end{array}\right.
$$




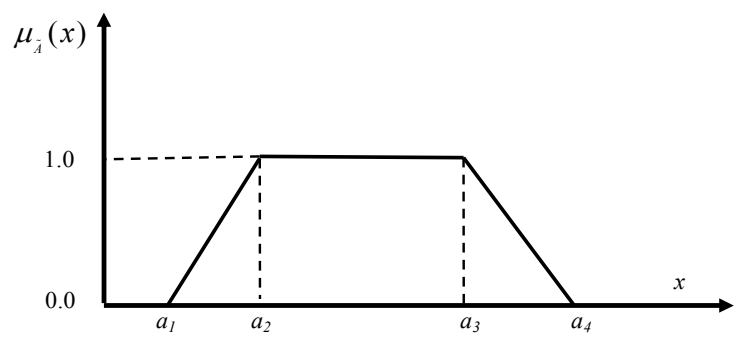

Fig. 2. A trapezoidal fuzzy number.

\subsection{Triangular fuzzy numbers}

The fuzzy number $\tilde{A}$ is a so-called triangular fuzzy number $\tilde{A}=\left(a_{1}, a_{2}=a_{3}, a_{4}\right), \quad a_{1} \leq a_{2}=a_{3} \leq a_{4} \quad$ if its membership function $\mu_{\tilde{A}}(x): R \rightarrow[0,1]$ is equal to

$$
\mu_{\tilde{A}}(x)=\left\{\begin{array}{cc}
\left(\frac{x-a_{1}}{a_{2}-a_{1}}\right) & x \in\left(a_{1}, a_{2}\right] \\
\left(\frac{a_{4}-x}{a_{4}-a_{3}}\right) & x \in\left[a_{3}, a_{4}\right) \\
0 & \text { others }
\end{array}\right.
$$

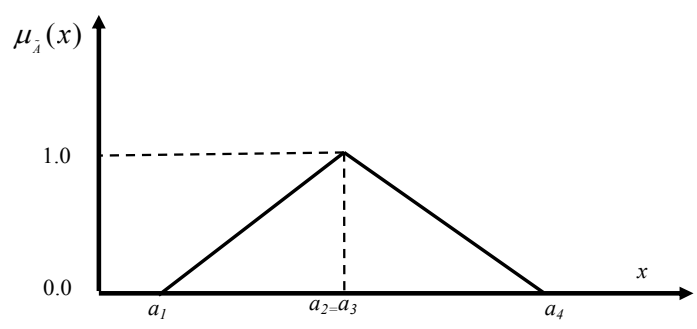

Fig. 3. A triangular fuzzy number.

\section{A new approach: Area-Based Ranking of Fuzzy Numbers}

In this work, a new area-based approach is proposed for ranking fuzzy numbers. Our method can be applied to most-used fuzzy numbers that are trapezoidal fuzzy numbers and triangular fuzzy numbers. Against many other methods' complexities, the proposed model is based on area measurement, which is very easy to calculate and has a visual understandability. By the help of a simple VBA code written by us, anyone can rank either triangular or trapezoidal fuzzy numbers. When compared with the other area based ranking methods, the proposed method is simpler and does not need tremendous mathematical calculations and formulations.

An index that measures the possibility of one fuzzy number being greater than another will be determined. That preference index will be illustrated by $I(\omega) \in[0,1]$ and it is determined by Eq. (4):

$$
I(\omega)=\frac{S_{\text {favor }}^{l}+S_{\text {favor }}^{r}+S_{\text {joint }}}{S_{A}+S_{B}}
$$

Using the areas as shown in Fig. 4, the preference index can be determined as in the following standard form, as given in Eq.(5):

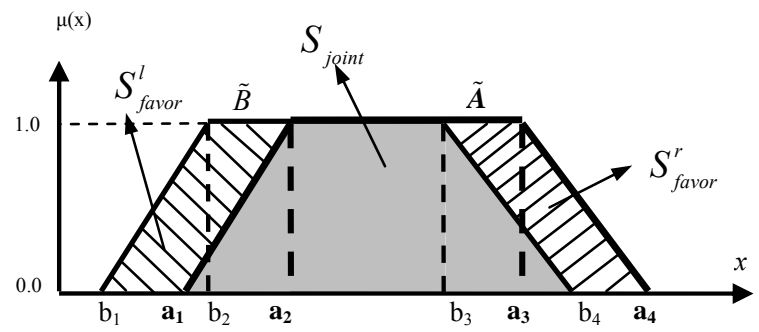

Fig. 4. Comparison of fuzzy numbers.

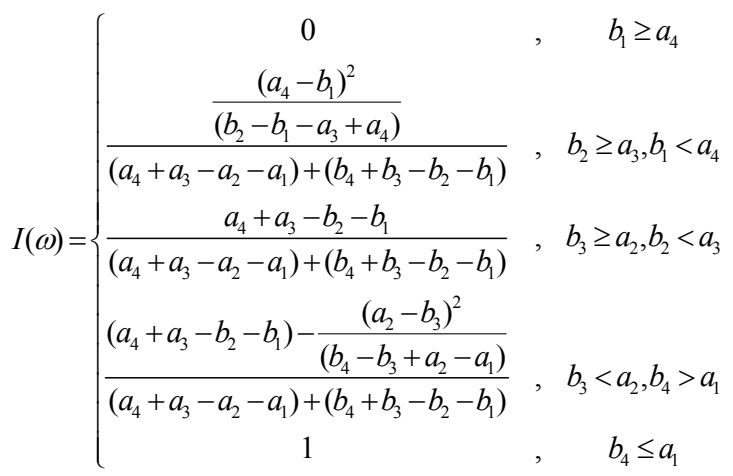

and the fuzzy preference relation $\left(P_{K T}\right)$ of the fuzzy numbers will be determined as following:

$$
P_{K T}(\tilde{A}, \tilde{B})=\left\{\begin{array}{lc}
\tilde{A} \succ \tilde{B} & \text { if } I(w) \in(0.5,1] \\
\tilde{A}=\tilde{B} & \text { if } I(w)=0.5 \\
\tilde{B} \succ \tilde{A} & \text { if } I(w) \in[0,0.5)
\end{array}\right.
$$

Calculation of index $I(\omega)$ is the key factor in our method. Two different trapezoidal fuzzy numbers are illustrated in Fig. 4. As it is seen, the area that is not overlapping is named $S_{\text {favor }}^{l}$ for the left side and $S_{\text {favor }}^{r}$ for the right side. $S_{\text {joint }}$ is the intersection area of these fuzzy numbers. $S_{A}$ and $S_{B}$ are the areas of the fuzzy numbers $\tilde{A}$ and $\tilde{B}$ consecutively. 
If the outcome of Eq. (5) is larger than 0.5, this means that the fuzzy number $\tilde{A}$ is preferred to $\tilde{B}$. The following figures (Figs. 5-8) can more clarify the calculation:

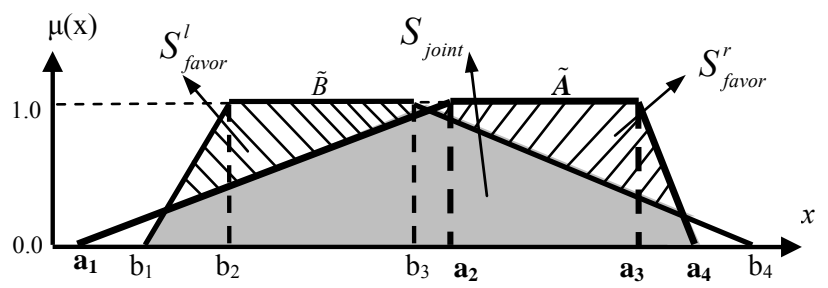

Fig. 5. Illustration of preference index calculation.

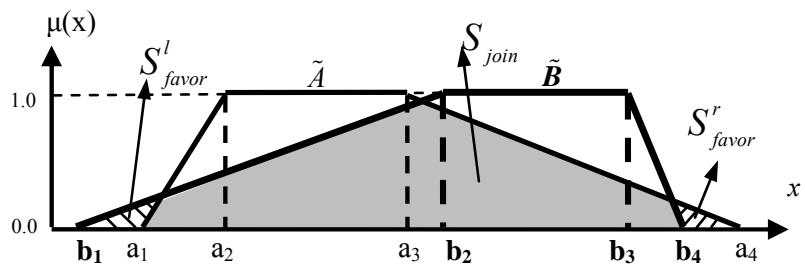

Fig. 6. An example for the second row of Eq. (5)

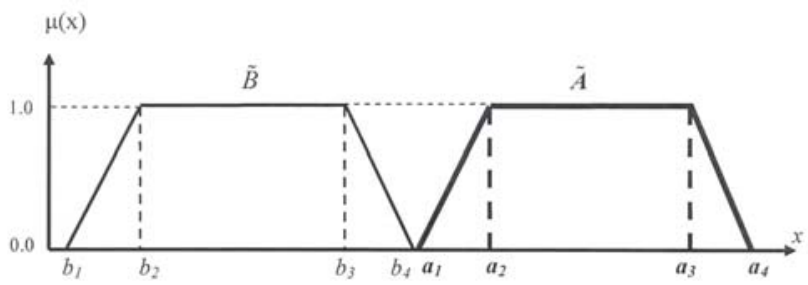

Fig. 7. An example for the fourth row of Eq. (5).

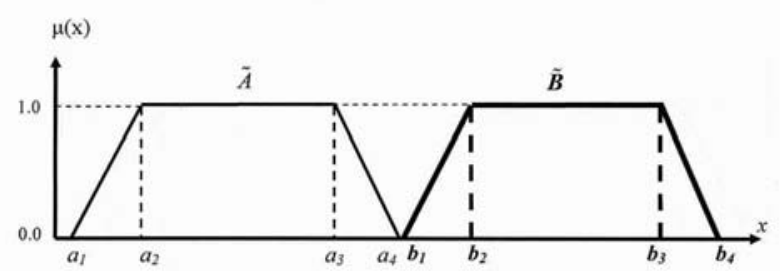

Fig. 8. An example for the fifth row of Eq. (5).

For example, in Fig. 6 let the fuzzy numbers $\tilde{A}$ and $\tilde{B}$ take the following values, respectively: $(2,3,4,8)$ and $(1,5,6,7)$. Then, from Eq. (5) we find the preference index: $I(\omega)=0.438$. Therefore, we can infer that the fuzzy number $\tilde{A}$ is smaller than the fuzzy number $\tilde{B}$ with a possibility of 0.438 . One can see and calculate these values easily by VBA code given in appendix. Writing this code is simple in OMSExcel VBA and someone can easily embed this code in any programming code also.

Our method can be applied to both triangular and trapezoidal fuzzy numbers. Ranking more than two fuzzy numbers is also very easy in our method. At first, pair wise ranking is carried out between all fuzzy numbers, then based on these pair wise orderings, a final order of the $n$ fuzzy numbers is attempted. Let us rank some triangular and trapezoidal fuzzy numbers by the methods summarized in this section and our proposed approach.

Let the triangular fuzzy numbers be:

$T \tilde{R} I 1=(0.20,0.30,0.50), T \tilde{R} I 2=(0.17,0.32,0.58)$,

$T \tilde{R} I 3=(0.25,0.40,0.70)$.

In addition, let the trapezoidal fuzzy numbers be:

$T \tilde{R} A 1=(0.20,0.30,0.40,0.50)$,

$T \tilde{R} A 2=(0.25,0.40,0.55,0.70)$,

$T \tilde{R} A 3=(0.20,0.25,0.45,0.60)$.

Final fuzzy number rankings for the methods explained before are illustrated in Table 2 .

As seen from Table 2 all triangular fuzzy number rankings are the same while trapezoidal fuzzy number rankings are different in some methods. For example, Dubois and Prade's ${ }^{20}$ PD method, Yager's ${ }^{31}$ weighted mean method, and Yager's ${ }^{33}$ area measurement method display dissimilar rankings. Dubois and Prade' $\mathrm{s}^{20} \mathrm{PD}$ method and Baas and Kwakernaak's ${ }^{8}$ conditional fuzzy set Approach give the same result informing three trapezoidal fuzzy numbers are equal. Yager's ${ }^{31}$ weighted mean method gives a different ranking order for these trapezoidal fuzzy numbers. Our method produces the same results for triangular fuzzy numbers with a less computational effort. In addition, it gives the same rank as Yager's ${ }^{33}$ area measurement method and Chen's ${ }^{29}$ fuzzy max and min method methods for trapezoidal fuzzy numbers. The ranking results by Fortemps and Roubens, ${ }^{, 7}$ area compensation method are completely the same as our method's since both methods are based on area measurement.

Our method has some advantages over Fortemps and Roubens ${ }^{7}$ method. They can be counted as follows: our method considers both joint and disjoint areas where as Fortemps and Roubens ${ }^{, 7}$ method considers only disjoint areas. With Fortemps and Roubens ${ }^{7}$ method, anybody has to calculate related areas using huge computational 
Table 2. Methods and their results.

\begin{tabular}{lrr}
\hline \multicolumn{1}{c}{ Methods } & Triangular & Trapezoidal \\
\hline Dubois and Prade's ${ }^{20}$ PD Method & $T \tilde{R} I 3>T \tilde{R} I 2>T \tilde{R} I 1$ & $T \tilde{R} A 3=T \tilde{R} A 2=T \tilde{R} A 1$ \\
Yager's ${ }^{31}$ Weighted Mean Method & $T \tilde{R} I 3>T \tilde{R} I 2>T \tilde{R} I 1$ & $T \tilde{R} A 3>T \tilde{R} A 2>T \tilde{R} A 1$ \\
Yager's ${ }^{33}$ Area Measurement Approach & $T \tilde{R} I 3>T \tilde{R} I 2>T \tilde{R} I 1$ & $T \tilde{R} A 2>T \tilde{R} A 3>T \tilde{R} A 1$ \\
Chen's $^{29}$ Fuzzy Max and Min Method & $T \tilde{R} I 3>T \tilde{R} I 2>T \tilde{R} I 1$ & $T \tilde{R} A 2>T \tilde{R} A 3>T \tilde{R} A 1$ \\
Baas and Kwakernaak's ${ }^{8}$ Conditional Fuzzy Set Approach & $T \tilde{R} I 3>T \tilde{R} I 2>T \tilde{R} I 1$ & $T \tilde{R} A 3=T \tilde{R} A 2=T \tilde{R} A 1$ \\
Fortemps and Roubens ${ }^{7}$ Area Compensation Method & $T \tilde{R} I 3>T \tilde{R} I 2>T \tilde{R} I 1$ & $T \tilde{R} A 2>T \tilde{R} A 3>T \tilde{R} A 1$ \\
Kahraman and Tolga's Area Based Approach & $T \tilde{R} I 3>T \tilde{R} I 2>T \tilde{R} I 1$ & $T \tilde{R} A 2>T \tilde{R} A 3>T \tilde{R} A 1$ \\
\hline
\end{tabular}

effort where as our method defines a unique formula for this computation.

The criteria developed by Wang and Kerre's ${ }^{41}$ have become a standard to measure the capability of ranking methods for fuzzy numbers. Hence, the proposed ranking method is examined with respect to Wang and Kerre's axioms in the following.

\section{Investigation with respect to Wang and Kerre's ${ }^{41}$ axioms}

Wang and Kerre ${ }^{42}$ classify ordering indices into three categories. In the first class, each index is associated with a mapping $F$ from the set of fuzzy quantities to the real line $\mathfrak{R}$ in order to transform the involved fuzzy quantities into real numbers. Fuzzy quantities are then compared according to the corresponding real numbers. In the second class, reference set(s) is (are) set up and all the fuzzy quantities to be ranked are compared with the reference set(s). In the last class, a fuzzy relation is constructed to make pair-wise comparisons between the fuzzy quantities involved. These pair-wise comparisons serve as a basis to obtain the final ranking orders. Therefore, the proposed ranking approach $P_{K T}$ take place within the last class.

At the beginning of our investigation, the following remarks should be given. $S$ is the set of fuzzy quantities for which the method $M$ can be applied and $\mathscr{A}$ is a finite subset of $S$. $A \succ B$ by $M$ on $\mathscr{A}$ can be explained as "two elements $A$ and $B$ in $A$ satisfy that $A$ has a higher ranking than $B$ when $M$ is applied to the fuzzy quantities in $\mathscr{A}$ ". " $A \sim B$ " by $M$ on $\mathscr{A}$ " and " $A \succsim B$ by $M$ on $\mathscr{A}$ " are similarly interpreted ${ }^{41}, P_{K T}$ is the fuzzy preference relation on $\mathscr{A}$ calculated from Eq. (5).

Wang and $\mathrm{Kerre}^{41}$ propose the following axioms as the reasonable properties of ordering fuzzy quantities for an ordering approach $M$.

$\mathbf{A}_{1}$ For an arbitrary finite subset $\mathscr{A}$ of $S$ and $A \in \mathscr{A}$, $A \succsim A$ by $M$ on $\mathcal{A}$.

$\mathbf{A}_{2}$ For an arbitrary finite subset $\mathcal{A}$ of $S$ and $(A, B) \in \mathcal{A}^{2}, A \succsim B$ and $B \succsim A$ by $M$ on $\mathscr{A}$, we should have " $A \sim B$ " by $M$ on $\mathscr{A}$.

$\mathbf{A}_{3}$ For an arbitrary finite subset $\mathscr{A}$ of $S$ and $(A, B, C) \in \mathcal{A}^{3}, A \succsim B$ and $B \succsim C$ by $M$ on $\mathscr{A}$, we should have $A \succsim C$ by $M$ on $\mathscr{A}$.

It is easy to prove that any ranking approach meets these three axioms ${ }^{41}$. Hence, it is not needed to prove these axioms for our method. Wang and Kerre ${ }^{41}$,s other axioms are given in the following:

$\mathbf{A}_{4}$ For an arbitrary finite subset $\mathscr{A}$ of $S$ and $(A, B) \in \mathscr{A}^{2}, \inf \operatorname{supp}(A)>\sup \operatorname{supp}(B)$, we should have $A \succsim B$ by $M$ on $\mathscr{A}$.

$\mathbf{A}^{\prime}{ }_{4}$ For an arbitrary finite subset $\mathscr{A}$ of $S$ and $(A, B) \in \mathscr{A}^{2}, \inf \operatorname{supp}(A)>\sup \operatorname{supp}(B)$, we should have $A \succ B$ by $M$ on $A$.

Since $\mathbf{A}_{4}^{\prime}$ is stronger that $\mathbf{A}_{4}$, only proof of $\mathbf{A}_{4}^{\prime}$ will be justified.

Assume $A=\left\{A_{1}, A_{2}, \ldots, A_{n}\right\}$ is the set of fuzzy quantities to be ranked, $A_{1} \neq \varnothing, A_{2} \neq \varnothing$, and if $A_{1}$ and $A_{2}$ are fuzzy numbers, they could be denoted as $A_{1}=\left(a_{11}, a_{12}, a_{13}, a_{14}\right), \quad A_{2}=\left(a_{21}, a_{22}, a_{23}, a_{24}\right), \quad$ and inf $\operatorname{supp}\left(A_{1}\right)>\sup \operatorname{supp}\left(A_{2}\right)$. 
Proposition 1. Assume the involved fuzzy quantities are fuzzy numbers. Then $P_{K T}$ satisfies $\boldsymbol{A}_{4}^{\prime}$.

Proof: When $\inf \operatorname{supp}\left(A_{1}\right)>\sup \operatorname{supp}\left(A_{2}\right)$, Let $a_{11}=\inf \operatorname{supp}\left(A_{1}\right), \quad a_{14}=\sup \operatorname{supp}\left(A_{1}\right) \quad$ and $a_{21}=\inf \operatorname{supp}\left(A_{2}\right), a_{24}=\sup \operatorname{supp}\left(A_{2}\right)$, it is easy to obtain from Eq. (5)'s $5^{\text {th }}$ row, $a_{11}>a_{24}$. Hence, $P_{K T}\left(A_{1}, A_{2}\right)=1$ and $P_{K T}\left(A_{2}, A_{1}\right)=0$. By Proposition 4.5(2) in Wang and Kerre ${ }^{43}$ 's study, $P_{K T}$ satisfies $\mathbf{A}_{4}^{\prime}$.

$\mathbf{A}_{5}$ Let $S$ and $S^{\prime}$ be two arbitrary finite sets of fuzzy quantities in which $M$ can be applied and $A$ and $B$ are in $S \cap S^{\prime}$. We obtain the ranking order $A \succ B$ by $M$ on $S^{\prime}$ iff $A \succ B$ by $M$ on $S$.

Proposition 2. $P_{K T}$ is consistent on $\mathcal{A}$.

Proof: " $P_{K T}$ is consistent" means transitivity holds, so transitivity of $P_{K T}$ needs to be demonstrated.

Proposition 2.1. $P_{K T}$ is transitive, i.e., for any $A_{1}, A_{2}$, and $A_{3} \in \mathcal{A}, \quad$ if $\quad P_{K T}\left(A_{1}, A_{2}\right)>1 / 2, \quad$ and $P_{K T}\left(A_{2}, A_{3}\right)>1 / 2$, then $P_{K T}\left(A_{1}, A_{3}\right)>1 / 2$.

Proof: From Eq. (5) $P_{K T}\left(A_{1}, A_{2}\right)>1 / 2 \Leftrightarrow A_{1} \succsim A_{2}$ and $P_{K T}\left(A_{2}, A_{3}\right)>1 / 2 \Leftrightarrow A_{2} \succsim A_{3}$, then from $\mathbf{A}_{3}$ if $A_{1} \succsim A_{2}$, and $\quad A_{2} \succsim A_{3}$, then $\quad A_{1} \succsim A_{3}$. Now, $A_{1} \succsim A_{3} \Leftrightarrow P_{K T}\left(A_{1}, A_{3}\right)>1 / 2$. So transitivity holds for $P_{K T}$ i.e. $P_{K T}$ is consistent.

Proposition 3. If a fuzzy relation $P$ is consistent, then the ordering approach based on P by Procedure 1 (or Procedure 1') as indicated in Wang and Kerre's ${ }^{43}$ study satisfies $\mathbf{A}_{5}$.

$$
\begin{aligned}
& \text { Proof: Under their assumption } \\
& A \sim B \Leftrightarrow P(A, B)=P(B, A) \text { and } \\
& A \succ B \Leftrightarrow P(A, B)>P(B, A) \text { (or } \\
& A \prec B \Leftrightarrow P(A, B)<P(B, A)) \text {, i.e. the ranking order of } A
\end{aligned}
$$

Proposition 4. Assume the involved fuzzy quantities are fuzzy numbers. Then $P_{K T}$ satisfies $\mathbf{A}_{5}$.

Proof: The mentioned fuzzy relation is consistent by Proposition 2, and hence according to Proposition 3, it satisfies $\mathbf{A}_{5}$.
$\mathbf{A}_{6}$ Let $A, B, A+C$ and $B+C$ be elements of $S$. If $A \succsim B$ by $M$ on $\{A, B\}$, then $A+C \succsim B+C$ by $M$ on $\{A+C, B+C\}$.

$\mathbf{A}_{6}$ If $A \succ B$ by $M$ on $\{A, B\}$, then $A+C \succ B+C$ by $M$ on $\{A+C, B+C\}$ when $C \neq \varnothing$.

Proposition 5: If the involved fuzzy quantities are fuzzy numbers, then $P_{K T}$ satisfies $\mathbf{A}_{6}$.

Proof: Assume $A_{i}=\left(a_{i 1}, a_{i 2}, a_{i 3}, a_{i 4}\right)(i=1,2,3)$. From $A_{1} \succsim A_{2}$ by $P_{K T}$ on $\left\{A_{1}, A_{2}\right\}$, we have $a_{11}>a_{24}$, and let $a_{11}^{\prime}=\left(a_{11}+a_{31}\right), \quad a_{12}^{\prime}=\left(a_{12}+a_{32}\right), \quad a_{23}^{\prime}=\left(a_{23}+a_{33}\right)$, $a_{24}^{\prime}=\left(a_{24}+a_{34}\right) . \quad \forall A_{3}$, it is always true $a_{24}^{\prime}>a_{11}^{\prime}$, $a_{23}^{\prime}<a_{12}^{\prime}$, and by the $4^{\text {th }}$ row of Eq. (5) $P_{K T}\left(A_{1}+A_{3}, A_{2}+A_{3}\right)>1 / 2$. Therefore, $A_{1}+A_{3} \succsim A_{2}+A_{3}$ by $P_{K T}$ on $\left\{A_{1}+A_{3}, A_{2}+A_{3}\right\}$.

$\mathbf{A}_{7}$ Let $A, B, A C$ and $B C$ be elements of $S$ and $C \geq 0 . A \succsim B$ by $M$ on $\{A, B\}$ implies $A C \succsim B C$ by $M$ on $\{A C, B C\}$.

$P_{K T}$ does not satisfy $\mathbf{A}_{7}$.

\section{Example.}

$A_{1}=(0,0.5,0.5,0.7) A_{2}=(0.2,0.5,0.5,0.6)$, and $A_{3}=(0,0.9,0.9,1)$.

$A_{2} \succsim A_{1}$ and $A_{1} A_{3} \succsim A_{2} A_{3}$ by $P_{K T}$ on $\left\{A_{1}, A_{2}\right\}$ and $\left\{A_{1} A_{3}, A_{2} A_{3}\right\}$ respectively.

From all proofs above, one can see $P_{K T}$ satisfies all the axioms except $\mathbf{A}_{7}$. Therefore, the developed ordering procedure is reasonable according to the Wang and Kerre's ${ }^{41}$ axioms.

Now, let us see how this method is used in multicriteria decision-making problems.

\section{Applications to Decision-Making}

Fuzzy ranking methods are often used in fuzzy decision making-processes and it plays an important role. Our method simplifies the ranking process in decisionmaking. To illustrate it, we will give some examples of our method in decision-making methods named fuzzy scoring method, Fuzzy Analytic Hierarchy Process (AHP) method, and fuzzy TOPSIS method.

Let the fuzzy numbers $\tilde{A}$ and $\tilde{B}$ be triangular, then the basic operations on them are given in Eqs. (7-8):

$$
\begin{aligned}
& \tilde{A} \otimes \tilde{B} \cong\left(a_{1} \times b_{1}, a_{2} \times b_{2}, a_{3} \times b_{3}\right) \\
& \tilde{A} \oplus \tilde{B}=\left(a_{1}+b_{1}, a_{2}+b_{2}, a_{3}+b_{3}\right)
\end{aligned}
$$


If the fuzzy numbers $\tilde{A}$ and $\tilde{B}$ are trapezoidal, the basic operations on them are given in Eqs. (9-10).

$$
\begin{aligned}
& \tilde{A} \otimes \tilde{B} \cong\left(a_{1} \times b_{1}, a_{2} \times b_{2}, a_{3} \times b_{3}, a_{4} \times b_{4}\right) \\
& \tilde{A} \oplus \tilde{B}=\left(a_{1}+b_{1}, a_{2}+b_{2}, a_{3}+b_{3}, a_{4}+b_{4}\right)
\end{aligned}
$$

\subsection{Multi-criteria decision-making using fuzzy scoring}

In the example of fuzzy scoring method, Bonissone's ${ }^{44}$ approach will be used. The performance of an alternative with respect to the attributes can easily be computed by the following formula:

$$
\tilde{U}_{i}=\sum_{j=1}^{n} \tilde{w}_{j} \tilde{r}_{i j}
$$

where $\tilde{w}_{j}$ and $\tilde{r}_{i j}$ represent the weight and scoring of attributes, respectively. After the calculation of $\tilde{U}_{i}$ values by Eq. (11), the ranking is obtained by our method. For example, three alternatives of advanced manufacturing systems, FMS-1, FMS-2, and FMS-3 will be assessed with respect to four attributes: engineering effort $\left(X_{1}\right)$, flexibility $\left(X_{2}\right)$, net present worth $\left(X_{3}\right)$, and integration ability $\left(X_{4}\right)$. The decision matrix is as follows:

$$
E=\begin{array}{ccccc} 
& X_{1} & X_{2} & X_{3} & X_{4} \\
F M S_{1} & \text { fair } & \text { good } & \text { fair } & \text { good } \\
F M S_{2} & \text { fair } & \text { very good } & \text { bad } & \text { good } \\
F M S_{3} & \text { very bad } & \text { very good } & \text { very good } & \text { very bad }
\end{array}
$$

The weight vector is given as;

\section{$\tilde{w}=$ (important, more or less important, unimportant, very important)} where very unimportant: $(0,0,0.2,0.3)$; unimportant:
$(0.2,0.3,0.3,0.4)$; more or less unimportant: $(0.3,0.4$, $0.4,0.5)$; indifferent: $(0.4,0.5,0.5,0.6)$; more or less important: $(0.5,0.6,0.6,0.7)$; important: $(0.6,0.7,0.7$, $0.8)$; very important: $(0.7,0.8,0.8,1.0)$.

The fuzzy set with each linguistic term is as follows: very bad: $(0,0,0.2,0.3)$; bad: $(0.2,0.3,0.3,0.4)$; more or less bad: $(0.3,0.4,0.4,0.5)$; fair: $(0.4,0.5,0.5,0.6)$; more or less good: $(0.5,0.6,0.6,0.7)$; good: $(0.6,0.7$, $0.7,0.8)$; very good: $(0.7,0.8,0.8,1.0)$.

Then, the fuzzy utilities for the alternatives are computed as given:

$$
\begin{aligned}
& \tilde{U}_{1}=\sum_{j=1}^{4} \tilde{w}_{j} \tilde{x}_{1 j}(0.6,0.7,0.7,0.8) \otimes(0.4,0.5,0.5,0.6) \\
&(0.5,0.6,0.6,0.7) \otimes(0.6,0.7,0.7,0.8) \\
& \oplus(0.2,0.3,0.3,0.4) \otimes(0.4,0.5,0.5,0.6) \\
& \oplus(0.7,0.8,0.8,1.0) \otimes(0.6,0.7,0.7,0.8) \\
&=(1.04,1.48,1.48,2.08) \\
& \tilde{U}_{2}=\sum_{j=1}^{4} \tilde{w}_{j} \tilde{x}_{2 j}=(0.6,0.7,0.7,0.8) \otimes(0.4,0.5,0.5,0.6) \\
& \oplus(0.5,0.6,0.6,0.7) \otimes(0.7,0.8,0.8,1.0) \\
& \oplus(0.2,0.3,0.3,0.4) \otimes(0.2,0.3,0.3,0.4) \\
& \oplus(0.7,0.8,0.8,1.0) \otimes(0.6,0.7,0.7,0.8) \\
&=(1.05,1.48,1.48,2.14) \\
& \tilde{U}_{3}=\sum_{j=1}^{4} \tilde{w}_{j} \tilde{x}_{3 j}=(0.6,0.7,0.7,0.8) \otimes(0.0,0.0,0.2,0.3) \\
& \oplus(0.5,0.6,0.6,0.7) \otimes(0.7,0.8,0.8,1.0) \\
& \oplus(0.2,0.3,0.3,0.4) \otimes(0.7,0.8,0.8,1.0) \\
& \oplus(0.7,0.8,0.8,1.0) \otimes(0.0,0.0,0.2,0.3) \\
&=(0.49,0.72,1.02,1.64)
\end{aligned}
$$

The obtained fuzzy utilities are illustrated in Figure 9.

The preference indexes $I\left(\omega_{1}\right), I\left(\omega_{2}\right)$, and $I\left(\omega_{3}\right)$

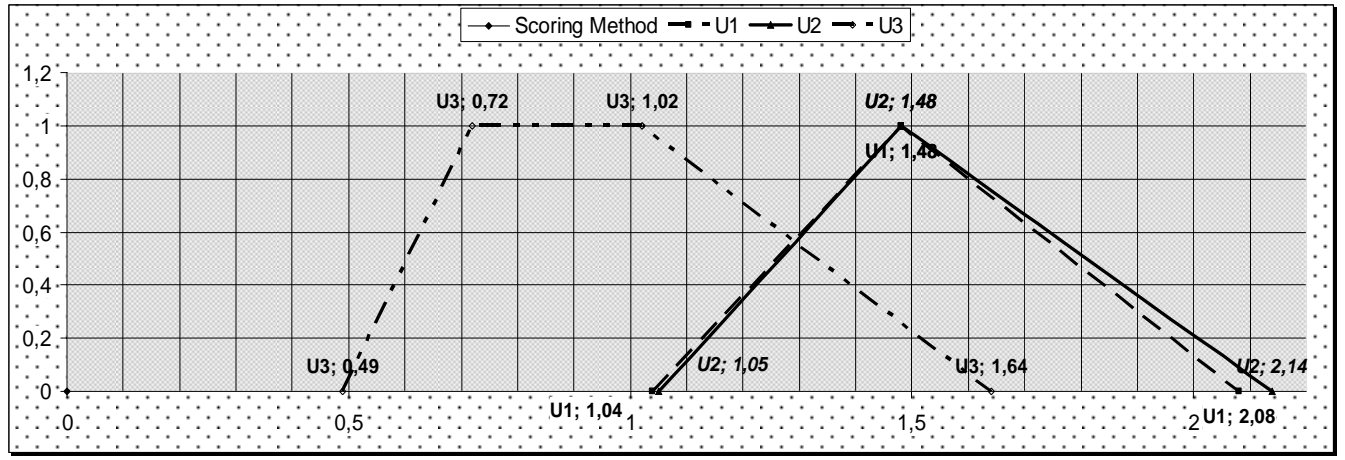

Fig. 9. The Fuzzy utilities of scoring method. 
which represent $\tilde{U}_{1}>\tilde{U}_{2}, \quad \tilde{U}_{1}>\tilde{U}_{3}$, and $\tilde{U}_{2}>\tilde{U}_{3}$, respectively can be calculated from Eq. (5). The results are: $I\left(\omega_{1}\right)=0.484\left(\tilde{U}_{1}<\tilde{U}_{2}\right), \quad I\left(\omega_{2}\right)=0.864\left(\tilde{U}_{1}>\tilde{U}_{3}\right)$, $I\left(\omega_{3}\right)=0.869\left(\tilde{U}_{2}>\tilde{U}_{3}\right)$ with inferences in parenthesis. Final ranking can be found as follows: $\tilde{U}_{2}>\tilde{U}_{1}>\tilde{U}_{3}$.

\subsection{Multi-criteria decision-making using fuzzy AHP}

Buckley ${ }^{45}$ extended Saaty's AHP method to incorporate fuzzy comparison ratios $a_{i j}$.

Steps of Buckley's approach are shown in the following steps.

Step 1: Consult the decision maker and obtain the comparison matrix $C$ whose elements are $\tilde{t}_{i j}=\left(k_{i j}, l_{i j}, m_{i j}, n_{i j}\right)$, where all $i$ and $j$ are trapezoidal fuzzy numbers.

Step 2: The fuzzy weights $w_{i}$ can be calculated as follows. The geometric mean for each row is determined as:

$$
\tilde{z}_{i}=\left[\prod_{j=1}^{n} \tilde{t}_{i j}\right]^{1 / n} \text {, for all } i
$$

The fuzzy weight $w_{i}$ is given as:

$$
w_{i}=\tilde{z}_{i} \oplus\left[\sum_{j=1}^{n} \tilde{z}_{j}\right]^{-1}
$$

Step 2 is repeated for all the fuzzy performance scores.

Step3: The fuzzy weights and fuzzy performance scores are aggregated. The fuzzy utilities $\tilde{U}_{i}, \forall i$, are based on

$$
\tilde{U}_{i}=\sum_{j=1}^{n} \tilde{w}_{j} \tilde{r}_{i j}, \forall i
$$

For clarifying the vagueness, a short example is given. A ceramic factory is looking for a general manager. There are three applicants for this position. The company is also looking for four attributes from these applicants. These attribute are "leadership", "problem solving skill", "communication skill", and "experimentation". The expert opinions about the relative importance of a pair of attributes are shown in Tables 3-7.
Table 3. Pair-wise Comparison of Applicants for Leadership.

$\mathrm{Al}_{\cdot 1}$
$\mathrm{Al}_{\cdot 2}$
$\mathrm{Al}_{\cdot 3}$$\left[\begin{array}{llc}\mathrm{Al}_{\cdot 1} & \multicolumn{1}{c}{\mathrm{Al}_{\cdot 2}} & \mathrm{Al}_{\cdot 3} \\ (1,1,1,1) & (1,2,2,3) & (2,2,4,4) \\ (1 / 3,1 / 2,1 / 2,1) & (1,1,1,1) & (1,2,2,3) \\ (1 / 4,1 / 4,1 / 2,1 / 2) & (1 / 3,1 / 2,1 / 2,1) & (1,1,1,1)\end{array}\right]$

Table 4. Pair-wise Comparison of Applicants for Problem Solving Skill.

$\mathrm{Al}_{\cdot 1}$
$\mathrm{Al}_{\cdot 2}$
$\mathrm{Al}_{\cdot 3}$$\left[\begin{array}{ccc}\mathrm{Al}_{\cdot 1} & \multicolumn{1}{c}{\mathrm{Al}_{\cdot 2}} & \mathrm{Al}_{\cdot 3} \\ (1,1,1,1) & (1 / 4,1 / 3,1 / 3,1 / 2) & (1,1,2,2) \\ (2,3,3,4) & (1,1,1,1) & (3,3,4,4) \\ (1 / 2,1 / 2,1,1) & (1 / 4,1 / 4,1 / 3,1 / 3) & (1,1,1,1)\end{array}\right]$

Table 5. Pair-wise Comparison of Applicants for Communication Skill.

$\mathrm{Al}_{\cdot 1}$
$\mathrm{Al}_{\cdot 2}$
$\mathrm{Al}_{\cdot 3}$$\left[\begin{array}{ccc}\mathrm{Al}_{\cdot 1} & \mathrm{Al}_{\cdot 2} & \multicolumn{1}{c}{\mathrm{Al} \cdot 3} \\ (1,1,1,1) & (6,6,7,7) & (3,3,4,4) \\ (1 / 7,1 / 7,1 / 6,1 / 6) & (1,1,1,1) & (1 / 2,1 / 2,1,1) \\ (1 / 4,1 / 4,1 / 3,1 / 3) & (1,1,2,2) & (1,1,1,1)\end{array}\right]$

Table 6. Pair-wise Comparison of Applicants for Experimentation
$\begin{array}{ll}\mathrm{Al}_{\cdot 1} & \begin{array}{c}\mathrm{Al}_{\cdot 1} \\ \mathrm{Al}_{\cdot 2} \\ \mathrm{Al}_{\cdot 3}\end{array} \\ (1,1,1,1) \\ (5,6,6,7) \\ (1 / 2,1 / 2,1,1)\end{array}$
$\mathrm{Al} .2$
$\mathrm{Al}_{.3}$

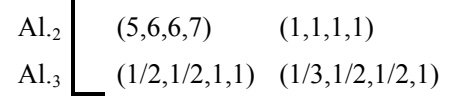
$(1,1,2,2)$
$(1,2,2,3)$
$(1,1,1,1)$

Table 7. Pair-wise Comparison of Four Attributes.

$\mathrm{X}_{1}$
$\mathrm{X}_{2}$
$\mathrm{X}_{3}$
$\mathrm{X}_{4}$$\left[\begin{array}{llcl}(1,1,1,1) & \multicolumn{1}{c}{\mathrm{X}_{2}} & \mathrm{X}_{3} & \multicolumn{1}{c}{\mathrm{X}_{4}} \\ (1 / 3,1 / 2,1 / 2,1) & (1,2,2,3) & (2,2,3,3) & (1 / 3,1 / 3,1 / 3,1 / 3) \\ (1 / 3,1 / 3,1 / 2,1 / 2) & (1 / 2,1 / 2,1,1) & (1,1,2,2) & (1,2,2,3) \\ (3,3,3,3) & (2,3,3,4) & (2,2,2,2) & (1,1,1,1)\end{array}\right]$

Via Eqs. (12-14), one can easily find the $\tilde{U}_{i}$ values as follows: $\quad \tilde{U}_{1}=(0.1651,0.2471,0.4513,0.6893)$, $\tilde{U}_{2}=(0.2764,0.4143,0.6126,0.9588)$, $\tilde{U}_{3}=(0.0830,0.1161,0.2229,0.3406)$.

Finally these values are ranked using Eq. 6 and it is obtained as follows $\tilde{U}_{2}>\tilde{U}_{1}>\tilde{U}_{3}$ and seen on Fig. 10 . 


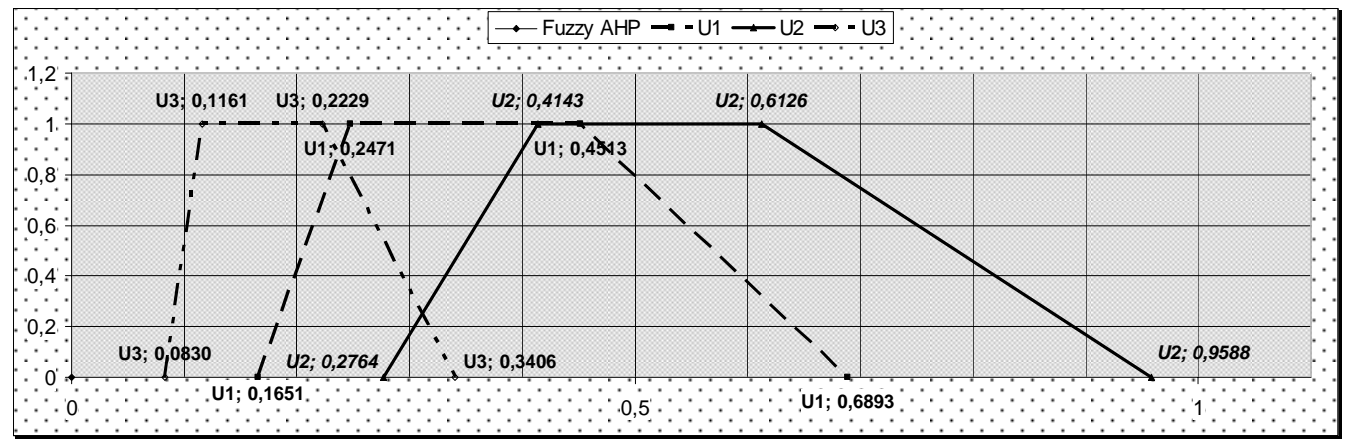

Fig. 10. The Fuzzy utilities of Fuzzy AHP.

\subsection{Multi-criteria decision-making using fuzzy TOPSIS}

One of the main methods for multi-criteria decisionmaking is fuzzy TOPSIS. Let us show how our ranking method is used in this method. Yang and Hung ${ }^{46}$ apply the following steps for the methodology of Fuzzy TOPSIS.

For fuzzy TOPSIS, if the fuzzy numbers $\tilde{A}$ and $\tilde{B}$ are triangular, the vertex method is defined to calculate the distance between them, as in Eq. (15):

$$
d(\tilde{A}, \tilde{B})=\sqrt{\frac{1}{3}\left[\left(a_{1}-b_{1}\right)^{2}+\left(a_{2}-b_{2}\right)^{2}+\left(a_{3}-b_{3}\right)^{2}\right]}
$$

If the fuzzy numbers $\tilde{A}$ and $\tilde{B}$ are trapezoidal, the vertex method is defined to calculate the distance between them as in Eq. $(16)^{47}$ :

$d(\tilde{A}, \tilde{B})=\sqrt{\frac{\left[\left(a_{1}-b_{1}\right)^{2}+2\left(a_{2}-b_{2}\right)^{2}+2\left(a_{3}-b_{3}\right)^{2}+\left(a_{4}-b_{4}\right)^{2}\right]}{6}}$

Brouwer $^{48}$ summarizes many distance calculation methods. In our work, the vertex method will be used because of its simplicity.

The following property is valid for both fuzzy triangular and fuzzy trapezoidal numbers: Let $\tilde{A}, \tilde{B}$, and $\tilde{C}$ be three triangular or trapezoidal fuzzy numbers. The fuzzy number $\tilde{B}$ is closer to fuzzy number $\tilde{A}$ than the other fuzzy number $\tilde{C}$ if, and only if, $d(\tilde{A}, \tilde{B})<d(\tilde{A}, \tilde{C})$.

The fuzzy multi-attribute decision making (MADM) can be concisely expressed in matrix format as in Eqs. (17) and (18).

$$
\begin{aligned}
& \begin{array}{llllll}
\mathrm{Cr}_{1} & \mathrm{Cr}_{2} & \mathrm{Cr}_{3} & \ldots & \mathrm{Cr}_{n}
\end{array} \\
& \tilde{D}=\begin{array}{c}
A l_{1} \\
A l_{2} \\
A l_{3} \\
\vdots \\
A l_{m}
\end{array}\left[\begin{array}{ccccc}
\tilde{x}_{11} & \tilde{x}_{12} & \tilde{x}_{13} & \ldots & \tilde{x}_{1 n} \\
\tilde{x}_{21} & \tilde{x}_{22} & \tilde{x}_{23} & \ldots & \tilde{x}_{2 n} \\
\tilde{x}_{31} & \tilde{x}_{32} & \tilde{x}_{33} & \ldots & \tilde{x}_{3 n} \\
\vdots & \vdots & \vdots & \ddots & \vdots \\
\tilde{x}_{m 1} & \tilde{x}_{m 2} & \tilde{x}_{m 3} & \ldots & \tilde{x}_{m n}
\end{array}\right] \\
& \tilde{W}=\left[\tilde{w}_{1}, \tilde{w}_{2}, \ldots, \tilde{w}_{n}\right]
\end{aligned}
$$

Where $\quad \tilde{x}_{i j}, i=1,2, \ldots, m, j=1,2, \ldots, n \quad$ and $\tilde{w}_{j}, j=1,2, \ldots, n$ are triangular or trapezoidal fuzzy numbers. If they are triangular: $\tilde{x}_{i j}=\left(a_{i j}, b_{i j}, c_{i j}\right)$ and $\tilde{w}_{j}=\left(w_{j 1}, w_{j 2}, w_{j 3}\right)$, if they are trapezoidal: $\tilde{x}_{i j}=\left(a_{i j}, b_{i j}, c_{i j}, d_{i j}\right)$ and $\tilde{w}_{j}=\left(w_{j 1}, w_{j 2}, w_{j 3}, w_{j 4}\right)$.

Note that $\tilde{x}_{i j}$ is the performance rating of the $i$ th alternative with respect to the $j$ th attribute, $C r_{j}$ and $\tilde{w}_{j}$ represents the weight of the $j$ th attribute, $C r_{j}$.

The normalized fuzzy decision matrix denoted by $\tilde{R}$ is shown in Eq. (19):

$$
\tilde{R}=\left[\tilde{r}_{i j}\right]_{m \times n}
$$

The weighted fuzzy normalized decision matrix is shown as in Eq. (20): 


$$
\begin{aligned}
\tilde{V} & =\left[\begin{array}{cccccc}
\tilde{v}_{11} & \tilde{v}_{12} & \ldots & \tilde{v}_{1 j} & \ldots & \tilde{v}_{1 n} \\
\tilde{v}_{21} & \tilde{v}_{22} & \ldots & \tilde{v}_{2 j} & \ldots & \tilde{v}_{2 n} \\
\vdots & \vdots & \ddots & \vdots & \ddots & \vdots \\
\tilde{v}_{i 1} & \tilde{v}_{i 2} & \ldots & \tilde{v}_{i j} & \ldots & \tilde{v}_{i n} \\
\vdots & \vdots & \ddots & \vdots & \ddots & \vdots \\
\tilde{v}_{m 1} & \tilde{v}_{m 2} & \ldots & \tilde{v}_{m j} & \ldots & \tilde{v}_{m n}
\end{array}\right] \\
& =\left[\begin{array}{ccccccc}
\tilde{w}_{1} \tilde{r}_{11} & \tilde{w}_{2} \tilde{r}_{12} & \ldots & \tilde{w}_{j} \tilde{r}_{1 j} & \ldots & \tilde{w}_{n} \tilde{r}_{1 n} \\
\tilde{w}_{1} \tilde{r}_{21} & \tilde{w}_{2} \tilde{r}_{22} & \ldots & \tilde{w}_{j} \tilde{r}_{2 j} & \ldots & \tilde{w}_{n} \tilde{r}_{2 n} \\
\vdots & \vdots & \ddots & \vdots & \ddots & \vdots \\
\tilde{w}_{1} \tilde{r}_{i 1} & \tilde{w}_{2} \tilde{r}_{i 2} & \ldots & \tilde{w}_{j} \tilde{r}_{i j} & \ldots & \tilde{w}_{n} \tilde{r}_{i n} \\
\vdots & \vdots & \ddots & \vdots & \ddots & \vdots \\
\tilde{w}_{1} \tilde{r}_{m 1} & \tilde{w}_{2} \tilde{r}_{m 2} & \ldots & \tilde{w}_{j} \tilde{r}_{m j} & \ldots & \tilde{w}_{n} \tilde{r}_{m n}
\end{array}\right]
\end{aligned}
$$

The proposed fuzzy TOPSIS procedure can be defined as follows:

Step 1: Choose the linguistic ratings $\left(\tilde{x}_{i j}, i=1,2, \ldots, n, j=1,2, \ldots, m\right)$ for alternatives with respect to the criteria and appropriate linguistic variables $\left(\tilde{w}_{j}, j=1,2, \ldots, n\right)$ to obtain the weights of the criteria.

Step 2: Construct the weighted normalized fuzzy decision matrix. The weighted normalized value $\tilde{V}$ is calculated by Eq. (20).

Step 3: Identify positive ideal $\left(A^{*}\right)$ and negative ideal $\left(A^{-}\right)$solutions. The fuzzy positive-ideal solution (FPIS, $A^{*}$ ) and fuzzy negative-ideal solution (FNIS, $\left.A^{-}\right)$are shown as in Eqs. (21) and (22):

$$
\begin{aligned}
A^{*} & =\left(\tilde{v}_{1}^{*}, \tilde{v}_{2}^{*}, \ldots \tilde{v}_{n}^{*}\right) \\
& =\left\{\left(\max _{i} \tilde{v}_{i j} \mid i=1,2, \ldots, m\right), j=1,2, \ldots, n\right\} \\
A^{-} & =\left(\tilde{v}_{1}^{-}, \tilde{v}_{2}^{-}, \ldots \tilde{v}_{n}^{-}\right) \\
& =\left\{\left(\min _{i} \tilde{v}_{i j} \mid i=1,2, \ldots, m\right), j=1,2, \ldots, n\right\}
\end{aligned}
$$

Our area-based ranking method is offered at this step for ranking $\tilde{v}_{i j}(i=1,2, \ldots, m)$ values for each $j$ th attribute. For FPIS, the greatest one; for FNIS, the lowest one among these fuzzy numbers should be taken.

Step 4: Calculate separation measures. The distance of each alternative from $A^{*}$ and $A^{-}$can be currently calculated using Eqs. (23) and (24).

$$
d_{i}^{*}=\sum_{j=1}^{n} d\left(\tilde{v}_{i j}, \tilde{v}_{j}^{*}\right), i=1,2, \ldots, m
$$

$$
d_{i}^{-}=\sum_{j=1}^{n} d\left(\tilde{v}_{i j}, \tilde{v}_{j}^{-}\right), i=1,2, \ldots, m
$$

Step 5: Calculate similarities to ideal solution. This step solves the similarities to an ideal solution by Eq. (25):

$$
C C_{i}=\frac{d_{i}^{-}}{d_{i}^{*}+d_{i}^{-}}
$$

Step 6: Rank preference order. Choose an alternative with maximum $C C_{i}^{*}$ or rank alternatives according to

\begin{tabular}{|c|c|c|c|c|c|c|}
\hline No. & $\mathrm{Cr}_{\cdot 1}$ & $\mathrm{Cr}_{\cdot 2}$ & $\mathrm{Cr}_{.3}$ & $\mathrm{Cr}_{.4}$ & $\mathrm{Cr}_{.5}$ & $\mathrm{Cr}_{6} 6$ \\
\hline $\mathrm{Al}_{.1}$ & $\mathrm{H}$ & $\mathrm{M}$ & $\mathrm{VL}$ & VL & $\mathrm{VL}$ & $\mathrm{H}$ \\
\hline $\mathrm{Al}_{.2}$ & M & $\mathrm{H}$ & M & M & VL & M \\
\hline $\mathrm{Al}_{.3}$ & M & $\mathrm{M}$ & VL & $\mathrm{H}$ & $\mathrm{L}$ & $\mathrm{L}$ \\
\hline $\mathrm{Al}_{.4}$ & $\mathrm{H}$ & $\mathrm{M}$ & $\mathrm{VL}$ & $\mathrm{H}$ & M & $\mathrm{M}$ \\
\hline $\mathrm{Al}_{.5}$ & M & M & $\mathrm{VL}$ & $\mathrm{H}$ & $\mathrm{L}$ & $\mathrm{M}$ \\
\hline $\mathrm{Al}_{.6}$ & VL & VL & $\mathrm{VH}$ & $\mathrm{L}$ & $\mathrm{L}$ & $\mathrm{H}$ \\
\hline $\mathrm{Al}_{.7}$ & $\mathrm{~L}$ & $\mathrm{M}$ & $\mathrm{VL}$ & $\mathrm{M}$ & $\mathrm{L}$ & $\mathrm{VL}$ \\
\hline $\mathrm{Al}_{.8}$ & $\mathrm{H}$ & $\mathrm{M}$ & VL & M & VL & M \\
\hline $\mathrm{Al} .9$ & $\mathrm{H}$ & $\mathrm{H}$ & VL & $\mathrm{L}$ & $\mathrm{VL}$ & $\mathrm{M}$ \\
\hline $\mathrm{Al}_{\cdot 10}$ & $\mathrm{VL}$ & $\mathrm{M}$ & $\mathrm{VL}$ & $\mathrm{M}$ & $\mathrm{M}$ & $\mathrm{H}$ \\
\hline $\mathrm{Al}_{.11}$ & $\mathrm{VH}$ & $\mathrm{H}$ & $\mathrm{VH}$ & $\mathrm{VH}$ & $\mathrm{VH}$ & $\mathrm{VH}$ \\
\hline $\mathrm{Al}_{\cdot 12}$ & M & $\mathrm{M}$ & $\mathrm{VL}$ & $\mathrm{L}$ & $\mathrm{L}$ & $\mathrm{M}$ \\
\hline $\mathrm{Al}_{\cdot 13}$ & $\mathrm{~L}$ & $\mathrm{M}$ & $\mathrm{VL}$ & $\mathrm{H}$ & $\mathrm{L}$ & $\mathrm{VL}$ \\
\hline $\mathrm{Al}_{.14}$ & M & $\mathrm{M}$ & VL & $\mathrm{L}$ & $\mathrm{M}$ & $\mathrm{M}$ \\
\hline $\mathrm{Al}_{15}$ & $\mathrm{VH}$ & $\mathrm{H}$ & VL & VH & $\mathrm{VH}$ & $\mathrm{VH}$ \\
\hline $\mathrm{Al}_{.16}$ & $\mathrm{~L}$ & $\mathrm{H}$ & VL & $\mathrm{M}$ & $\mathrm{L}$ & $\mathrm{H}$ \\
\hline $\mathrm{Al}_{.17}$ & $\mathrm{H}$ & $\mathrm{M}$ & VL & $\mathrm{M}$ & $\mathrm{M}$ & VL \\
\hline $\mathrm{Al}_{.18}$ & $\mathrm{VH}$ & $\mathrm{VH}$ & $\mathrm{VL}$ & $\mathrm{H}$ & $\mathrm{M}$ & $\mathrm{VL}$ \\
\hline Weights & $\mathrm{H}$ & $\mathrm{H}$ & M & $\mathrm{L}$ & $\mathrm{H}$ & $\mathrm{M}$ \\
\hline
\end{tabular}
$C C_{i}^{*}$ in descending order.

To be more understandable, the example in Yang and Hung's ${ }^{46}$ study is going to be resolved in the following. We will not give the whole example for the sake of shortening the paper. Someone more interested on these details should look at Yang and Hung's ${ }^{46}$ paper.

Table 8. Decision matrix using fuzzy linguistic variables

The fuzzy linguistic variables of the decision matrix are given in Table 8 . With the fuzzy membership functions given in Table 9, the fuzzy linguistic variables are transformed into fuzzy triangular membership functions as shown in Table 10. 
Table 9. Transformation for fuzzy membership functions

\begin{tabular}{lcl}
\hline Rank & Attribute grade & Membership functions \\
\hline Very low (VL) & 1 & $(0.00,0.10,0.25)$ \\
Low (L) & 2 & $(0.15,0.30,0.45)$ \\
Medium (M) & 3 & $(0.35,0.50,0.65)$ \\
High (H) & 4 & $(0.55,0.70,0.85)$ \\
Very high (VH) & 5 & $(0.75,0.90,1.00)$ \\
\hline
\end{tabular}

The first step of fuzzy TOPSIS analysis and the fuzzy attribute weight are shown in Table 10.

Obtaining the weighted fuzzy decision matrix by Eq. (36) using Eq. (23) is the second step of fuzzy TOPSIS method. At the third step the fuzzy positive-ideal solution (FPIS, $A^{*}$ ) and the fuzzy negative-ideal solution (FNIS, $A^{-}$) have to be obtained. Differently from Yang and Hung's ${ }^{46}$ study, we use the area-based ranking approach (Eq. (5)) to find these values. The distance of each alternative from $A^{*}$ and $A^{-}$can be calculated using Eqs. (39) and (40). At the fifth step, the similarities to an ideal solution are solved by Eq. (41). Table 11 summarizes all these steps of fuzzy TOPSIS.

Finding the fuzzy positive-ideal solution (FPIS, $A^{*}$ ) and the fuzzy negative-ideal solution (FNIS, $A^{-}$) is the key factor in our method. Using Eq. (5) we rank the $\tilde{v}_{i j}$ $(i=1,2, \ldots, m, j=1,2, \ldots, n)$ values and, we find $v_{i}^{*}$ and $v_{i}^{-}$values for each criterion. For example, the ranking for the first criterion is obtained:

$$
\begin{aligned}
& \tilde{v}_{111}=\tilde{v}_{151}=\tilde{v}_{181}>\tilde{v}_{11}=\tilde{v}_{41}=\tilde{v}_{81}=\tilde{v}_{91}=\tilde{v}_{171}>\tilde{v}_{21} \\
& =\tilde{v}_{31}=\tilde{v}_{51}=\tilde{v}_{121}>\tilde{v}_{141}>\tilde{v}_{71}=\tilde{v}_{131}=\tilde{v}_{161}>\tilde{v}_{61}=\tilde{v}_{101}
\end{aligned}
$$

Then, $\quad v_{1}^{*}=\tilde{v}_{181}=(0.41,0.70,1.13) \quad$ and $v_{1}^{*}=\tilde{v}_{61}=(0.00,0.08,0.28)$ is obtained from this ranking. The other steps in fuzzy TOPSIS are applied in the same way as Yang and Hung's ${ }^{46}$ study.

\subsection{Some calculation corrections in Yang and Hung's ${ }^{46}$ paper}

Yang and Hung ${ }^{46}$ calculated $C C_{i}$ values as in Table 12.

Yang and Hung ${ }^{46}$ give the rank order using Table 12 as follows:

$$
\begin{aligned}
& A l .11>A l .15>A l .18>A l .4>A l .17>A l .8>A l .10> \\
& A l .4>A l .2>A l .16>A l .9>A l .5>A l .1>A l .3> \\
& A l .12>A l .6>A l .7>A l .13 .
\end{aligned}
$$

This rank order is obviously incorrect. According to the results above, the true rank order is obtained as:

$$
\begin{aligned}
& A l .11>A l .15>A l .18>A l .4>A l .2>A l .8>A l .16> \\
& A l .9>A l .17>A l .14>A l .5>A l .1>A l .10> \\
& A l .3>A l .12>A l .6>A l .7>A l .13 .
\end{aligned}
$$

\begin{tabular}{|c|c|c|c|c|c|c|}
\hline No. & $\mathrm{Cr}_{.1}$ & $\mathrm{Cr}_{.2}$ & $\mathrm{Cr}_{.3}$ & $\mathrm{Cr}_{4}$ & $\mathrm{Cr}_{.5}$ & $\mathrm{Cr}_{.6}$ \\
\hline $\mathrm{Al}_{.1}$ & $(0.55,0.70,0.85)$ & $(0.35,0.50,0.65)$ & $(0.00,0.10,0.25)$ & $(0.00,0.10,0.25)$ & $(0.00,0.10,0.25)$ & $(0.55,0.70,0.85)$ \\
\hline $\mathrm{Al}_{2}$ & $(0.35,0.50,0.65)$ & $(0.55,0.70,0.85)$ & $(0.35,0.50,0.65)$ & $(0.35,0.50,0.65)$ & $(0.00,0.10,0.25)$ & $(0.35,0.50,0.65)$ \\
\hline $\mathrm{Al}_{3}$ & $(0.35,0.50,0.65)$ & $(0.35,0.50,0.65)$ & $(0.00,0.10,0.25)$ & $(0.55,0.70,0.85)$ & $(0.15,0.30,0.45)$ & $(0.15,0.30,0.45)$ \\
\hline $\mathrm{Al}_{4}$ & $(0.55,0.70,0.85)$ & $(0.35,0.50,0.65)$ & $(0.00,0.10,0.25)$ & $(0.55,0.70,0.85)$ & $(0.35,0.50,0.65)$ & $(0.35,0.50,0.65)$ \\
\hline $\mathrm{Al}_{.5}$ & $(0.35,0.50,0.65)$ & $(0.35,0.50,0.65)$ & $(0.00,0.10,0.25)$ & $(0.55,0.70,0.85)$ & $(0.15,0.30,0.45)$ & $(0.35,0.50,0.65)$ \\
\hline $\mathrm{Al}_{6} 6$ & $(0.00,0.10,0.25)$ & $(0.00,0.10,0.25)$ & $(0.75,0.90,1.00)$ & $(0.15,0.30,0.45)$ & $(0.15,0.30,0.45)$ & $(0.55,0.70,0.85)$ \\
\hline $\mathrm{Al}_{.7}$ & $(0.15,0.30,0.45)$ & $(0.35,0.50,0.65)$ & $(0.00,0.10,0.25)$ & $(0.35,0.50,0.65)$ & $(0.15,0.30,0.45)$ & $(0.00,0.10,0.25)$ \\
\hline $\mathrm{Al}_{.8}$ & $(0.55,0.70,0.85)$ & $(0.35,0.50,0.65)$ & $(0.00,0.10,0.25)$ & $(0.35,0.50,0.65)$ & $(0.00,0.10,0.25)$ & $(0.35,0.50,0.65)$ \\
\hline $\mathrm{Al} .9$ & $(0.55,0.70,0.85)$ & $(0.55,0.70,0.85)$ & $(0.00,0.10,0.25)$ & $(0.15,0.30,0.45)$ & $(0.00,0.10,0.25)$ & $(0.35,0.50,0.65)$ \\
\hline $\mathrm{Al}_{10}$ & $(0.00,0.10,0.25)$ & $(0.35,0.50,0.65)$ & $(0.00,0.10,0.25)$ & $(0.35,0.50,0.65)$ & $(0.35,0.50,0.65)$ & $(0.55,0.70,0.85)$ \\
\hline $\mathrm{Al}_{11}$ & $(0.75,0.90,1.00)$ & $(0.55,0.70,0.85)$ & $(0.75,0.90,1.00)$ & $(0.75,0.90,1.00)$ & $(0.75,0.90,1.00)$ & $(0.75,0.90,1.00)$ \\
\hline $\mathrm{Al}_{12}$ & $(0.35,0.50,0.65)$ & $(0.35,0.50,0.65)$ & $(0.00,0.10,0.25)$ & $(0.15,0.30,0.45)$ & $(0.15,0.30,0.45)$ & $(0.35,0.50,0.65)$ \\
\hline $\mathrm{Al}_{13}$ & $(0.15,0.30,0.45)$ & $(0.35,0.50,0.65)$ & $(0.00,0.10,0.25)$ & $(0.55,0.70,0.85)$ & $(0.15,0.30,0.45)$ & $(0.00,0.10,0.25)$ \\
\hline $\mathrm{Al}_{14}$ & $(0.35,0.50,0.65)$ & $(0.35,0.50,0.65)$ & $(0.00,0.10,0.25)$ & $(0.15,0.30,0.45)$ & $(0.35,0.50,0.65)$ & $(0.35,0.50,0.65)$ \\
\hline $\mathrm{Al}_{.15}$ & $(0.75,0.90,1.00)$ & $(0.55,0.70,0.85)$ & $(0.00,0.10,0.25)$ & $(0.75,0.90,1.00)$ & $(0.75,0.90,1.00)$ & $(0.75,0.90,1.00)$ \\
\hline $\mathrm{Al}_{16}$ & $(0.15,0.30,0.45)$ & $(0.55,0.70,0.85)$ & $(0.00,0.10,0.25)$ & $(0.35,0.50,0.65)$ & $(0.15,0.30,0.45)$ & $(0.55,0.70,0.85)$ \\
\hline $\mathrm{Al}_{17}$ & $(0.55,0.70,0.85)$ & $(0.35,0.50,0.65)$ & $(0.00,0.10,0.25)$ & $(0.35,0.50,0.65)$ & $(0.35,0.50,0.65)$ & $(0.00,0.10,0.25)$ \\
\hline $\mathrm{Al}_{18}$ & $(0.75,0.90,1.00)$ & $(0.75,0.90,1.00)$ & $(0.00,0.10,0.25)$ & $(0.55,0.70,0.85)$ & $(0.35,0.50,0.65)$ & $(0.00,0.10,0.25)$ \\
\hline W & $(0.55,0.70,0.85)$ & $(0.55,0.70,0.85)$ & $(0.35,0.50,0.65)$ & $(0.15,0.30,0.45)$ & $(0.55,0.70,0.85)$ & $(0.35,0.50,0.65)$ \\
\hline
\end{tabular}

Fuzzy TOPSIS using our ranking approach produces the same order at first five alternatives but the rest of the ordering is different as follows:

Table 10. Fuzzy decision matrix and fuzzy attribute weights 
Table 11. Fuzzy TOPSIS Analysis

\begin{tabular}{|c|c|c|c|c|c|c|c|c|c|}
\hline No. & $\tilde{v}_{i 1}$ & $\tilde{v}_{i 2}$ & $\tilde{v}_{i 3}$ & $\tilde{v}_{i 4}$ & $\tilde{v}_{i 5}$ & $\tilde{v}_{i 6}$ & $d_{i}^{+}$ & $d_{i}^{-}$ & $C C_{i}$ \\
\hline$A l_{. I}$ & $(0.3,0.54,0.96)$ & $(0.19,0.39,0.74)$ & $(0,0.06,0.22)$ & $(0,0.03,0.15)$ & $(0,0.08,0.28)$ & $(0.19,0.39,0.74)$ & 2.0129 & 1.2170 & 0.3768 \\
\hline$A l .2$ & $(0.19,0.39,0.74)$ & $(0.3,0.54,0.96)$ & $(0.12,0.28,0.56)$ & $(0.05,0.17,0.39)$ & $(0,0.08,0.28)$ & $(0.12,0.28,0.56)$ & 1.7292 & 1.5010 & 0.4647 \\
\hline $\mathrm{Al}_{3}$ & $(0.19,0.39,0.74)$ & $(0.19,0.39,0.74)$ & $(0,0.06,0.22)$ & $(0.08,0.23,0.51)$ & $(0.08,0.23,0.51)$ & $(0.05,0.17,0.39)$ & 2.0266 & 1.2035 & 0.3726 \\
\hline $\mathrm{Al}_{.4}$ & $(0.3,0.54,0.96)$ & $(0.19,0.39,0.74)$ & $(0,0.06,0.22)$ & $(0.08,0.23,0.51)$ & $(0.19,0.39,0.74)$ & $(0.12,0.28,0.56)$ & 1.5604 & 1.6704 & 0.5170 \\
\hline$A l .5$ & $(0.19,0.39,0.74)$ & $(0.19,0.39,0.74)$ & $(0,0.06,0.22)$ & $(0.08,0.23,0.51)$ & $(0.08,0.23,0.51)$ & $(0.12,0.28,0.56)$ & 1.9012 & 1.3289 & 0.4114 \\
\hline$A l_{6}$ & $(0,0 . .08,0.28)$ & $(0,0.08,0.28)$ & $(0.26,0.5,0.87)$ & $(0.02,0.1,0.27)$ & $(0.08,0.23,0.51)$ & $(0.19,0.39,0.74)$ & 2.1300 & 1.0988 & 0.3403 \\
\hline$A l .7$ & $(0.08,0.23,0.51)$ & $(0.19,0.39,0.74)$ & $(0,0.06,0.22)$ & $(0.05,0.17,0.39)$ & $(0.08,0.23,0.51)$ & $(0,0.06,0.22)$ & 2.4003 & 0.8291 & 0.2567 \\
\hline Al. 8 & $(0.3,0.54,0 . .96)$ & $(0.19,0.39,0.74)$ & $(0,0.06,0.22)$ & $(0.05,0.17,0.39)$ & $(0,0.08,0.28)$ & $(0.12,0.28,0.56)$ & 1.9767 & 1.2529 & 0.3879 \\
\hline Al. 9 & $(0.3,0.54,0.96)$ & $(0.3,0.54,0.96)$ & $(0,0.06,0.22)$ & $(0.02,0.1,0.27)$ & $(0,0.08,0.28)$ & $(0.12,0.28,0.56)$ & 1.8876 & 1.3427 & 0.4157 \\
\hline$A l_{10}$ & $(0,0.08,0.28)$ & $(0.19,0.39,0.74)$ & $(0,0.06,0.22)$ & $(0.05,0.17,0.39)$ & $(0.19,0.39,0.74)$ & $(0.19,0.39,0.74)$ & 2.0219 & 1.2076 & 0.3739 \\
\hline$A l_{\cdot I I}$ & $(0.41,0.7,1.13)$ & $(0.3,0.54,0.96)$ & $(0.26,0.5,0.87)$ & $(0.11,0.3,0.6)$ & $(0.41,0.7,1.13)$ & $(0.26,0.5,0.87)$ & 0.1474 & 3.0808 & 0.9543 \\
\hline$A l_{12}$ & $(0.19,0.39,0.74)$ & $(0.19,0.39,0.74)$ & $(0,0.06,0.22)$ & $(0.02,0.1,0.27)$ & $(0.08,0.23,0.51)$ & $(0.12,0.28,0.56)$ & 2.0630 & 1.1667 & 0.3612 \\
\hline$A l_{13}$ & $(0.08,0.23,0.51)$ & $(0.19,0.39,0.74)$ & $(0,0.06,0.22)$ & $(0.08,0.23,0.51)$ & $(0.08,0.23,0.51)$ & $(0,0.06,0.22)$ & 2.3195 & 0.9102 & 0.2818 \\
\hline$A l_{14}$ & $(0.19,0.39,0.74)$ & $(0.19,0.39,0.74)$ & $(0,0.06,0.22)$ & $(0.02,0.1,0.27)$ & $(0.19,0.39,0.74)$ & $(0.12,0.28,0.56)$ & 1.8923 & 1.3373 & 0.4141 \\
\hline$A l_{15}$ & $(0.41,0.7,1.13)$ & $(0.3,0.54,0.96)$ & $(0,0.06,0.22)$ & $(0.11,0.3,0.6)$ & $(0.41,0.7,1.13)$ & $(0.26,0.5,0.87)$ & 0.6266 & 2.6016 & 0.8059 \\
\hline$A l_{16}$ & $(0.08,0.23,0.51)$ & $(0.3,0.54,0.96)$ & $(0,0.06,0.22)$ & $(0.05,0.17,0.39)$ & $(0.08,0.23,0.51)$ & $(0.19,0.39,0.74)$ & 1.8576 & 1.3735 & 0.4251 \\
\hline$A l_{17}$ & $(0.3,0.54,0.96)$ & $(0.19,0.39,0.74)$ & $(0,0.06,0.22)$ & $(0.05,0.17,0.39)$ & $(0.19,0.39,0.74)$ & $(0,0.06,0.22)$ & 1.8887 & 1.3412 & 0.4152 \\
\hline$A l_{18}$ & $(0.41,0.7,1.13)$ & $(0.41,0.7,1.13)$ & $(0,0.06,0.22)$ & $(0.08,0.23,0.51)$ & $(0.19,0.39,0.74)$ & $(0,0.06,0.22)$ & 1.3429 & 1.8851 & 0.5840 \\
\hline$A^{*}$ & $\tilde{v}_{1}^{*}=(0.41,0.7,1.13)$ & $\tilde{v}_{2}^{*}=(0.41,0.7,1.13)$ & $\tilde{v}_{3}^{*}=(0.26,0.5,0.87)$ & $\tilde{v}_{4}^{*}=(0.11,0.3,0.6)$ & $\tilde{v}_{5}^{*}=(0.41,0.7,1.13)$ & $\tilde{v}_{6}^{*}=(0.26,0.5,0.87)$ & & & \\
\hline$A^{-}$ & $\tilde{v}_{1}^{-}=(0,0.08,0.28)$ & $\tilde{r}_{2}^{-}=(0,0.08,0.28)$ & $\tilde{v}_{3}^{-}=(0,0.06,0.22)$ & $\tilde{v}_{4}^{-}=(0,0.03,0.15)$ & $\tilde{v}_{5}^{-}=(0,0.08,0.28)$ & $\tilde{v}_{6}^{-}=(0,0.06,0.22)$ & & & \\
\hline$W=$ & $\{(0.55,0.70,0.85)$ & $0.70,0.85),(0.35$, & $0.65),(0.15,0.30$ & $(0.55,0.70,0.85)$ & $5,0.50,0.65)\}$ & & & & \\
\hline
\end{tabular}

Table 12. $C C_{i}$ values calculated by Yang and Hung ${ }^{46}$

\begin{tabular}{|l|c|c|c|c|c|c|c|c|c|}
\hline $\begin{array}{l}\text { Alternative } \\
\text { No. }\end{array}$ & 1 & 2 & 3 & 4 & 5 & 6 & & 7 & 8 \\
\hline$C C_{i}$ & 0.25736 & 0.29178 & 0.25359 & 0.31299 & 0.26942 & 0.24198 & 0.22174 & 0.28298 & 0.27309 \\
\hline Order & 12 & 5 & 14 & 4 & 11 & 16 & 17 & 6 & 8 \\
\hline
\end{tabular}

Table 12. (Continued) $C C_{i}$ values calculated by Yang and Hung ${ }^{46}$

\begin{tabular}{|l|c|c|c|c|c|c|c|c|c|}
\hline $\begin{array}{l}\text { Alternative } \\
\text { No. }\end{array}$ & 10 & 11 & 12 & 13 & 14 & 15 & 16 & 17 & 18 \\
\hline$C C_{i}$ & 0.25513 & 0.49125 & 0.24952 & 0.21682 & 0.2713 & 0.43210 & 0.27548 & 0.27246 & 0.34258 \\
\hline Order & 13 & 1 & 15 & 18 & 10 & 2 & 7 & 9 & 3 \\
\hline
\end{tabular}

$A l .11>A l .15>A l .18>A l .4>A l .2>A l .16>A l .9>$

Al.17 > Al.14 > Al.5 > Al.8 > Al.1 >Al.10 > Al.3>

Al.12 $>$ Al.6 $>$ Al.13 $>$ Al.7.

\section{Conclusions}

In fuzzy decision-making problems, fuzzy ranking is one of the most-researched areas. In this study, fuzzy number ranking procedures are investigated. Then, an area-based ranking approach is offered for the shortages of the other ranking approaches. This new approach can 
be applied to most-used decision-making procedures that are fuzzy scoring, fuzzy AHP, and fuzzy TOPSIS. Generally, our approach produced same results however; in fuzzy TOPSIS, different results are reached.

For further study, application of that area-based fuzzy ranking approach to other decision-making approaches can be investigated. A formula for L-R type fuzzy numbers can be studied with the same logic of the formula developed for triangular and trapezoidal fuzzy numbers.

\section{References}

1. D. Dubois and H. Prade, Operations on fuzzy numbers, International Journal of Systems Science 9 (1978) 613626.

2. S. J. Chen, C. L. Hwang, and F. P. Hwang, Fuzzy Multiple Attribute Decision Making; Methods and Applications (Springer, Berlin, 1992).

3. V. Cross and M. Setnes, A generalized model for ranking fuzzy sets, in Proc. IEEE World Congress on Computational Intelligence 1 (1998), pp. 773-778.

4. A. N. S. Freeling, Fuzzy sets and decision analysis, IEEE Transactions on Systems, Man, and Cybernetics 10 (1980) 341-354.

5. G. Bortolan and R. Degani, A review of some methods for ranking fuzzy subsets, Fuzzy Sets and Systems 15 (1985) 1-19.

6. E. S. Lee and R. L. Li, Comparison of fuzzy numbers based on the probability measure of events, Computer and Mathematics with Applications 15 (1988) 887-896.

7. P. Fortemps, and M. Roubens, Ranking and defuzzication methods based on area compensation, Fuzzy Sets and Systems 82 (1996) 319-330.

8. S. M. Baas and H. Kwakernaak, Rating, and ranking of multiple aspect alternative using fuzzy sets, Automatica 13 (1977) 47-58

9. S. R. Watson, J. J. Weiss, and M. L. Donnell, Fuzzy decision analysis, IEEE Transactions on Systems, Man, and Cybernetics 9 (1979) 1-9.

10. J. F. Baldwin and N. C. Guild, A model for multi-criterial decision-making using fuzzy logic, Workshop of Fuzzy Reasoning (London, Queen Mary College, 1978).

11. R. R. Yager, On choosing between fuzzy subsets, Kybernetes 9 (1980) 151-154.

12. E. E. Kerre, The use of fuzzy set theory in electrocardiological diagnostics, in Approximate reasoning in Decision analysis, eds.: M. M. Gupta and E. Sanchez (North-Holland, Amsterdam, 1982) pp. 277-282.

13. K. Nakamura, Preference relation on a set of fuzzy utilities as a basis for decision making, Fuzzy Sets and Systems 20 (1986) 147-162.
14. W. Kolodziejczyk, Orlovsky's concept of decision making with fuzzy preference relation further results, Fuzzy Sets and Systems 19 (1986) 11-20.

15. L. Tran, and L. Duckstein, Comparison of fuzzy numbers using distance measure, Fuzzy sets and systems 130 (2002) 331-341.

16. J. M. Adamo, Fuzzy decision trees, Fuzzy sets and systems 4 (1980) 207-220.

17. J. J. Buckley and S. Chanas, A fast method of ranking alternatives using fuzzy numbers (Short communications), Fuzzy sets and systems 30 (1989) 337339.

18. S. Mabuchi, An approach to the comparison of fuzzy subsets with an $\alpha$-cut dependent index, IEEE Transactions on Systems, Man, and Cybernetics 18 (1988) 264-272.

19. L. H. Chen and H. W. Lu, An approximate approach for ranking fuzzy numbers based on left and right dominance, An International Journal of Computers and Mathematics with Applications 41 (2001) 1589-1602.

20. D. Dubois and H. Prade, Ranking of fuzzy numbers in the setting of possibility theory, Information Sciences $\mathbf{3 0}$ (1983) 183-224.

21. Y. Tsukamoto, P. N. Nikiforuk and M. M. Gupta, On the comparison of fuzzy sets using fuzzy chopping, in Control Science and Technology for Progress of Society, ed. H. Akashi (Pergamon Press, New York, 1983) pp. 4651 .

22. M. Delgado, J. Verdegay, and M. A. Villa, A procedure for ranking fuzzy numbers using fuzzy relations, Fuzzy Sets and Systems 26 (1988) 49-62.

23. C. H. Cheng, A new approach for ranking fuzzy numbers by distance method, Fuzzy Sets and Systems 95 (1998) 307-317.

24. S. Murakami, S. Maeda and S. Inamura, Fuzzy decision analysis on the development of centralized regional energy control system, in IFAC Symposium on Fuzzy Information, Knowledge Representation and Decision Analysis, (1983) pp. 363-368.

25. T. C. Chu and C. T. Tsao Ranking fuzzy numbers with an Area between the Centroid Point and Original Point, $A n$ International Journal of Computers and Mathematics with Applications 43 (2002) 111-117.

26. C. McCahone, "Fuzzy Set Theory Applied to Production and Inventory Control" Ph. D. Thesis, (Kansas State University, 1987).

27. R. Jain, Decision making in the presence of fuzzy variables, IEEE Transactions on Systems, Man, and Cybernetics 6 (1976) 698-703.

28. R. Jain, A procedure for multi-aspect decision making using fuzzy sets, International Journal of System 8 (1977) 1-7.

29. S. H. Chen, Ranking fuzzy numbers with maximizing set and minimizing set, Fuzzy Sets and Systems 17 (1985) 113-129.

30. S. J. Chen and C. L. Hwang, Fuzzy scoring of fuzzy number-A direct comparison index, in Fuzzy Multiple 
Attribute Decision Making; Methods and Applications, eds. S. J. Chen, C. L. Hwang and F. P. Hwang (Springer, Berlin, 1989) pp. 256-258.

31. R. R. Yager, On a general class of fuzzy connectives, Fuzzy Sets and Systems 4 (1980) 235-242.

32. D. Yong and L. Qi, A TOPSIS-based centroid-index ranking method of fuzzy numbers and its application to decision making, Cybernetics and Systems: An International Journal 36 (2005) 581-595.

33. R. R. Yager, A procedure for ordering fuzzy subsets of the unit interval, Information Sciences 24 (1981) 143161.

34. J. Efstathiou and R. Tong, Ranking fuzzy sets using linguistic preference relations, in Proceedings of the 10th International Symposium on Multiple-Valued Logic (Northwestern University, Evanston, 1980) pp. 137-142.

35. R. M. Tong and P.P. Bonissone, Linguistic solutions to fuzzy decision problems, in TIMS/Studies in the Management Science, ed.: H. J. Zimmermann (Elsevier, North Holland, 1984) pp. 323-334.

36. M. Modarres and S. Sadi-Nezhad, Ranking fuzzy numbers by preference ratio, Fuzzy Sets and Systems 118 (2001) 429-436.

37. S. Abbasbandy, and T. Hajjari, A new approach for ranking of trapezoidal fuzzy numbers, Computers \& Mathematics with Applications 57 (2009) 413-419.

38. C. C. Chen, and H.C. Tang, Ranking nonnormal $p$-norm trapezoidal fuzzy numbers with integral value, Computers \& Mathematics with Applications 56 (2008) 2340-2346.

39. Y. J. Wang, and H. S. Lee, The revised method of ranking fuzzy numbers with an area between the centroid and original points, Computers \& Mathematics with Applications 55 (2008) 2033-2042.

40. B. Asady, and A. Zendehnam, Ranking fuzzy numbers by distance minimization, Applied Mathematical Modelling, 31 (2007), 2589-2598.

41. X. Wang and E. E. Kerre, Reasonable properties for the ordering of fuzzy quantities (I), Fuzzy Sets and Systems 118 (2001) 375-385.

42. X. Wang, E. E. Kerre, On the classification and the dependencies of the ordering methods, in Fuzzy Logic Foundations and Industrial Applications, ed. D. Ruan (Kluwer Academic Publishers, Dordrecht, 1996), pp. 7388.

43. X. Wang and E. E. Kerre, Reasonable properties for the ordering of fuzzy quantities (II), Fuzzy Sets and Systems 118 (2001) 387-405.

44. P. P. Bonissone, A fuzzy set based linguistic approach: Theory and applications, in Approximate Reasoning in Decision Analysis, eds. M.M. Gupta and E. Sanchez, (North-Holland, 1982) pp. 329-339.

45. J. J. Buckley, Fuzzy hierarchical analysis, Fuzzy Sets and Systems 17 (1985) 233-247.
46. T. Yang and C. C. Hung, Multiple-attribute decision making methods for plant layout design problem, Robotics and Computer-Integrated Manufacturing 23 (2007) 126-137.

47. D. F. Li, Compromise ratio method for fuzzy multiattribute group decision making, Applied Soft Computing 7 (2007) 807-817.

48. R. K. Brouwer, Clustering feature vectors with mixed numerical and categorical attributes, International Journal of Computational Intelligence Systems 1 (2008) 285-298.

\section{Appendix}

VBA Code for ranking fuzzy numbers is given below:

Sub Preference_Index()

Dim A1, A2, A3, A4, B1, B2, B3, B4

Dim I, P1, P2, P3

Worksheets("fuzzy preference").Activate

A1 $=$ Cells $(2,1)$. Value
A2 $=$ Cells $(2,2)$. Value
A3 $=$ Cells $(2,3)$. Value
A4 $=$ Cells $(2,4)$. Value
B1 $=$ Cells $(2,5)$. Value
B2 $=$ Cells $(2,6)$. Value
B3 $=$ Cells $(2,7)$. Value
B4 $=$ Cells $(2,8)$. Value

If $\mathrm{B} 1>\mathrm{A} 4$ Or $\mathrm{B} 1=\mathrm{A} 4$ Then

$$
\mathrm{I}=0
$$

Elself B1 $<$ A4 And B2 $>$ A3 Or B1 $<$ A4 And B2 $=$ A3

Then

$$
\mathrm{I}=\left(\left((\mathrm{A} 4-\mathrm{B} 1)^{\wedge} 2\right) /(\mathrm{B} 2-\mathrm{B} 1-\mathrm{A} 3+\mathrm{A} 4)\right) /((\mathrm{A} 4+
$$$$
\mathrm{A} 3-\mathrm{A} 2-\mathrm{A} 1)+(\mathrm{B} 4+\mathrm{B} 3-\mathrm{B} 2-\mathrm{B} 1))
$$

End If

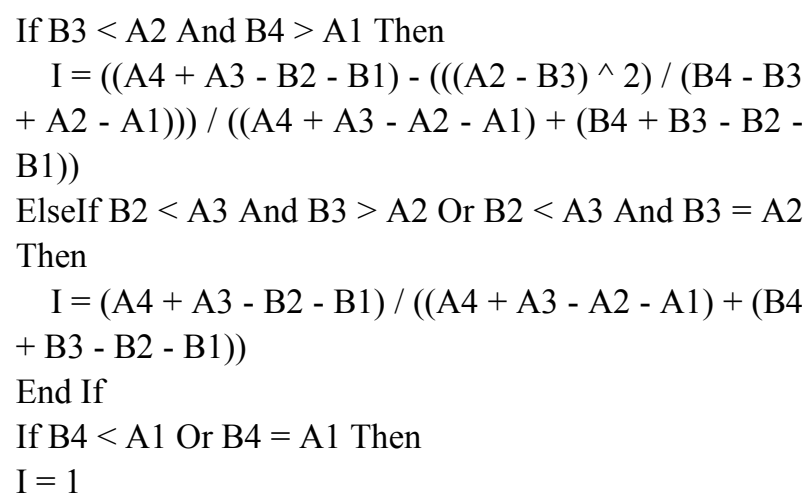


End If

If $\mathrm{I}>0.5$ Then

$\mathrm{P} 1=\mathrm{I}$

ElseIf $\mathrm{I}<0.5$ Then

P3 = I

Else

P2 = I

End If

'Output calculated fuzzy preference index

Cells $(5,3)$. Value $=\mathrm{P} 1$

Cells $(5,4)$. Value $=\mathrm{P} 2$

Cells $(5,5)$. Value $=\mathrm{P} 3$

End Sub 